Article

\title{
A Study on Multi-Objective Parametric Design Tool for Surround-Type Movable Shading Device
}

\author{
Ho-Jeong Kim *, Chang-Seok Yang and Hyeun Jun Moon \\ Department of Architecture, Dankook University, Yongin 16890, Korea; hsy7247@naver.com (C.-S.Y.); \\ hmoon@dankook.ac.kr (H.J.M.) \\ * Correspondence: hojeong_kim@dankook.ac.kr; Tel.: +82-31-8005-3710; Fax: +82-31-8005-3723
}

Received: 2 November 2019; Accepted: 8 December 2019; Published: 11 December 2019

\begin{abstract}
This study presents a multi-objective parametric design tool for four-axis surround-type movable shading device using solar position tracking in Seoul, South Korea. In order to explore large numbers of possible forms of shades, generic algorithms are utilized with real-time simulation of the performative criteria such as solar radiation, daylight glare probability (DGP), and solar shielding rate on window surface. This study outlines a workflow using a multi-objective engine called Octopus that runs within Grasshopper 3D, a parametric design tool, in addition to environmental performance simulation plug-in Ladybug. The workflow utilizes a performance-based design tool, which allows the designer to explore, sort, and filter solutions, and visually compare alternative solutions in terms of energy saving and indoor daylight quality in order to determine the optimal form of shade changing its shape every one hour. The result of deriving and analyzing the optimal shade shape through the genetic algorithm proposed in this study is as follows: On the one hand, on the summer solstice, shade shapes with shielding areas of almost 100\% should be derived to achieve the most effective reduction of the direct solar radiation. The proposed movable shading device reduced direct solar radiation by $52.40 \%$ and $57.20 \%$ in the south- and east-facing windows, respectively. On the other hand, in winter when solar heat gain is important, the absence of sunshade is optimal in terms of heating load. However, in order to improve the indoor light environment, it is confirmed that it is possible to derive a certain shape of sunshade according to the sun's trajectory. On the winter solstice, the problem of glare arises from 10:00 to 15:00 in the south and 10:00 in the east. Therefore, the proposed four-axis movable shading device can be configured to have a minimum protrusion length satisfying DGP less than 0.35 in winter.
\end{abstract}

Keywords: shading system; surround-type movable shade; genetic algorithm; solar radiation; daylight glare probability (DGP); solar shielding rate

\section{Introduction}

Achieving sustainable goals in the construction sector requires buildings that are both energy efficient and able to improve the indoor environment for occupants. The building envelope plays an important role in implementing this sustainable architecture [1] in order to enhance the Sustainable Development Goals 2030 by the United Nations. Recent facade design trends are faced with deteriorated thermal performance due to curtain wall application and increased window area ratio, which are the main causes of increased cooling load in summer. In order to improve the thermal vulnerability of the outer shell, many studies have attempted to improve energy demand performance by shielding the incoming solar radiation and applying external shade [2].

Shades attached to the building envelope can be divided into fixed and movable types. The design of a fixed shade is determined by the sun's altitude and azimuth at the time the shade is needed. On the one hand, horizontal shades are generally known to be most effective on the south side, 
and the protrusion length is estimated by considering the altitude angle of the sun. On the other hand, azimuth is an important determinant for the vertical shade used on the east or west side where the solar altitude is low. In order to increase the shielding rate while shortening the protrusion length, it is effective to install the vertical fins at short intervals. Eggcrate-shaped shades combined vertically and horizontally can be applied irrespective of orientation by considering both solar altitude and azimuth. However, one disadvantage is that the natural light performance is degraded due to excessive shielding.

In reality, it is a complex matter to determine the shape of an awning so that the orientation of the building varies and the awning is not unnecessarily over shaded. In particular, it is very difficult to determine the proper shade from the viewpoint of improving not only the thermal environment but also the indoor light environment. The shading forms shown in existing external shading studies [3-7] are mainly fixed on the outer skin such as overhang and side fin. However, fixed shading is unable to respond to changes in time and environment. In addition, heating costs can increase due to unnecessary sunshades. Therefore, the application of a movable shade as an alternative has been actively implemented in recent years.

Movable shades originated from the concept of climate-adaptive envelopes, which is a way of actively changing the shape and properties of buildings against climate change. As the shape of the external shade is actively changed according to the conditions, it is possible to control the environment in a more sophisticated manner in terms of thermal or light environment. Where fixed shades have been developed primarily for cooling load reduction, external movable shades have been developed in the form of Venetian blinds, awnings, roller blinds, and shutters, depending on the shape and manner of operation. This type has the advantage of controlling both the thermal and light environments by creating a suitable shield and controlling the amount of light. Although this type of variable shade is meaningful in terms of environmental performance control, it is limited in terms of securing the view and openness to the outside.

Therefore, in this study, a surround-type four-axis movable sunshade that can adjust both thermal and light conditions while having the advantages of both fixed and movable sunshades has been proposed. The surround-type shade proposed in this study is a system in which the horizontal and vertical parts are attached along the outside of the window to secure visual openness, while the protrusion length of each point changes with time according to the azimuth and altitude angle of the sun. The purpose of this study is to derive the appropriate shading form according to the time frame and to improve thermal and light improvement by using a parametric design methodology with environmental performance evaluation.

Research on movable sunshades has been attempted by various researchers, but has mostly consisted of research on control systems of movable sunshades such as venetian blinds, roller blinds, and shutters, as well as environmental performance [8-13]. The research on other forms of movable sunshades has been carried out to a limited extent due to the limitations of application and building performance simulation (BPS) tools. For example, venetian blinds and horizontal louvers, in the case of an external shading device with a conventional uniform shape, are controlled by slat angle control. However, this method is difficult to reflect the azimuth angle of the sun in the former case and the altitude angle of the sun in the latter case. Therefore, in order to properly reflect the altitude and azimuth of the sun, it is expected to be more effective to consider both vertical and horizontal elements of the shade. In addition, simulation and analysis of variable shade using a BPS tool are unable to provide environmental performance analysis that reflects shape changes of the movable shade.

In order to derive the optimal shade according to the solar trajectory, which is the subject of this study, it is necessary to evaluate the comparative advantages of environmental performances for a myriad of shapes with different displacements at each point. To this end, this study proposes a methodology to derive optimized alternatives using a parametric design. A parametric design is a process based on algorithmic thinking that enables the expression of parameters and design rules together, that define, encode, and clarify the relationship between design intent and design response. In this context, recent studies have sought to mutually optimize and combine various aspects to 
derive an optimized facade design [14,15]. Multi-objective algorithms have also become an essential element in performing such research. Several approaches utilize genetic algorithms to minimize energy consumption or derive the best facade solution according to window size, shape, orientation, and window area ratio [16-22].

Therefore, this study was carried out to derive the optimal shade form of the multi-axis driving-type shading device to satisfy several environmental parameters through a possible multi-objective design approach using genetic algorithms. The four-axis movable shading device is different from external shading and the four shafts of the corner are controlled by a push and pull method. The focus of this study is as follows: (1) to introduce an innovative surround-type shading device with variable vertical and horizontal elements, and (2) to discuss methods to minimize the solar radiation passing through the shading system and optimize the thermal performance of a building and light environment (i.e., DGP) for occupants at the same time. This study proposes a four-axis movable shading device for reducing direct solar radiation on window surface in summer and improving the light environment in winter considering the climate environment in Seoul, which is designed to identify the optimal sunshade shape at each hour. Proposed algorithms were used to derive various types of sunshade according to the position of the sun, and simulations of solar radiation, daylight glare, and solar shielding rate were simultaneously conducted to evaluate environmental performance.

\section{Materials and Methods}

\subsection{Overview of Proposed Parametric Algorithm and Multipurpose Optimization}

A parametric design algorithm allows a broad range of alternatives to be reviewed effectively according to diverse variables. Instead of simulating a specific shape of shade and simulating the environmental performance of a fixed form, the study simultaneously simulates environmental performance by linking an environmental performance assessment program to a parametric design algorithm to create shapes according to design rules.

The external variable shade system proposed in this study is designed to control the environment efficiently by constructing the appropriate shape according to the solar position. In order to do this, it is necessary to derive the best shape for each timeframe considering the altitude and azimuth angle of the sun, and the orientation of the building. In this study, a parametric algorithm was constructed using Grasshopper-Ladybug-Octopus to derive various shading shapes for each hour to simulate direct solar radiation on window surface, DGP, and solar shielding rate.

Grasshopper is a graphical algorithm editor that works with Rhino 3D program, allowing a designer to create various form alternatives by adjusting parameters that have a decisive impact on design, such as design rules and displacements. The Ladybug plug-in for Rhino 3D/Grasshopper software were used as the main environmental performance simulation tool to calculate direct solar radiation on window surface and DGP, and integrated with Grasshopper by writing a customized script with Paython to calculate solar shielding rate. Octopus plug-in was also integrated with Grasshopper to perform genetic optimization to achieve maximum shielding area with minimum length and to plot the results of the generated shade forms and performance criteria visually.

Since the biggest purpose of sunshade in summer was to block solar radiation, the amount of solar radiation on the windows was measured. In addition, regarding the light environment, the DGP was measured to determine if the glare could be prevented by a variable shade. In the case of indoor illuminance, it can be supplemented with artificial light sources, but the problem of glare has to be solved by shading. DGP (Wienold and Christoffersen, 2006) is the most recent index used to evaluate glare from daylight, and it was extracted by experimental data in private office spaces involving human test subjects (intolerable glare, DGP $\geq 0.45$; disturbing glare, $0.45>\mathrm{DGP} \geq 0.4,0.4>\mathrm{DGP} \geq$ 0.35 ; and imperceptible glare, $0.35>$ DGP) $[23,24]$. With regards to the solar shielding rate, it was calculated to investigate the relationship between solar radiation and indoor light environment changes. Ultimately, in terms of energy savings, it is ideal to derive the optimal shade based on the usage of 
heating, cooling, and lighting energy. However, this study was not a performance evaluation for a given form, and this was not realized due to the limitation of the simulation program that could be used to integrate with the parametric design tool that could generate various forms according to design rules.

Figure 1 shows the step-by-step flow of the proposed algorithm. First, in Stage 1, the position of the sun is set up according to the altitude and azimuth, and basic information such as model material, solar radiation, and glare measurement location are assigned. In Stage 2, various shade forms are derived by simultaneously applying design rules and evaluating performance criteria (DGP, solar radiation, and solar shielding rate). Finally, in Stage 3, the results of each performance criteria are listed in order, and then sorted and filtered to determine the most appropriate shape of the shade.

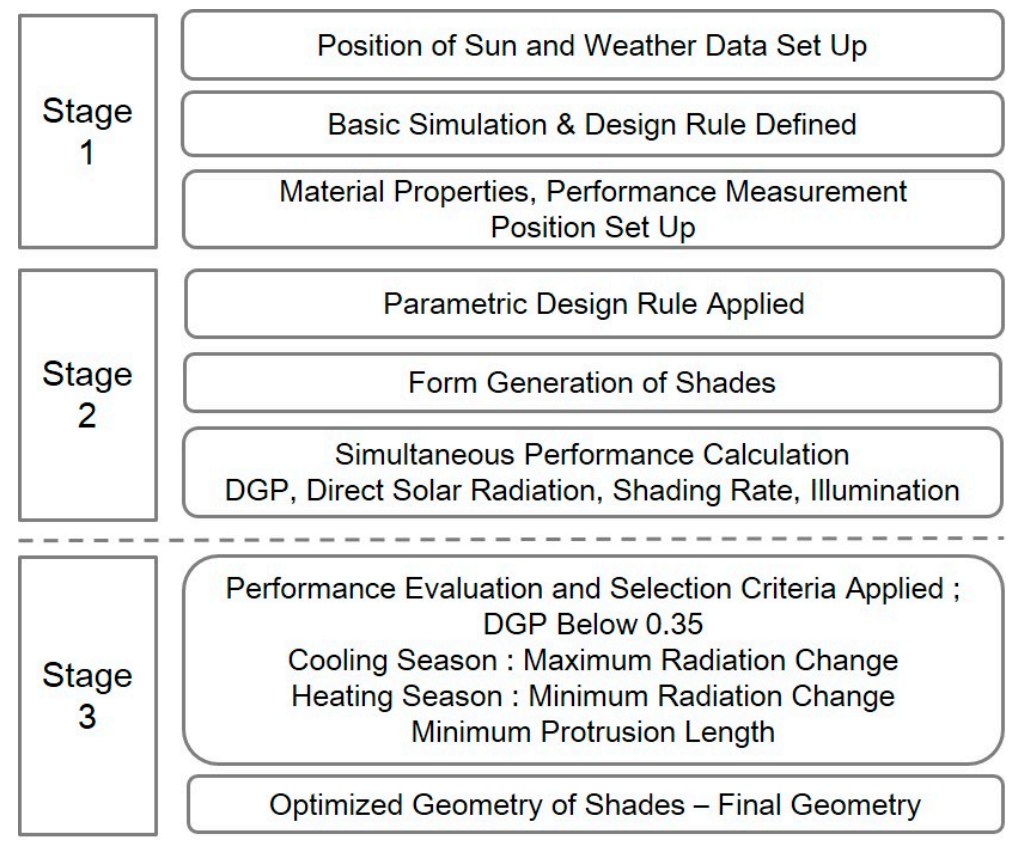

Figure 1. Workflow of the proposed algorithm and optimization.

This form-making approach allows the investigation of many design options and accelerates the design and selection process based on the environmental performance of the specific shade. An optimization stage was conducted with the main objective to select the shape of the shade with the DGP of 0.35 or less and at the same time have the lowest solar radiation on window surface for summer and the highest radiation for winter. If the solar radiation is similar or the same, the horizontal projection area is selected to be the smallest to ensure the highest degree of openness when viewed from the inside.

\subsection{Outline of the Four-Axis Movable Shading Device}

\subsubsection{Surround-Type Shade Overview}

The movable shading device discussed, in this study, is assumed to be a surround-type device made with a flexible fabric material fixed by vertical and horizontal pins, which is applicable to a punched window-type commonly found in medium-sized commercial or business facility buildings in Seoul, South Korea. As shown in Figure 2, the four-axis variable shading device applied in this study includes both vertical and horizontal elements. The shading device is composed of a driving part composed of four iron frames corresponding to lengths P1, P2, P3, and P4 and a flexible fabric material connected to the frames. The fabric material of the sunshade is polyester with PVC coating. The surround-type shade has a larger shielding area because the vertical and horizontal elements that 
change over time are combined, making it possible to reduce the protrusion length along the sun's azimuth and altitude angles.

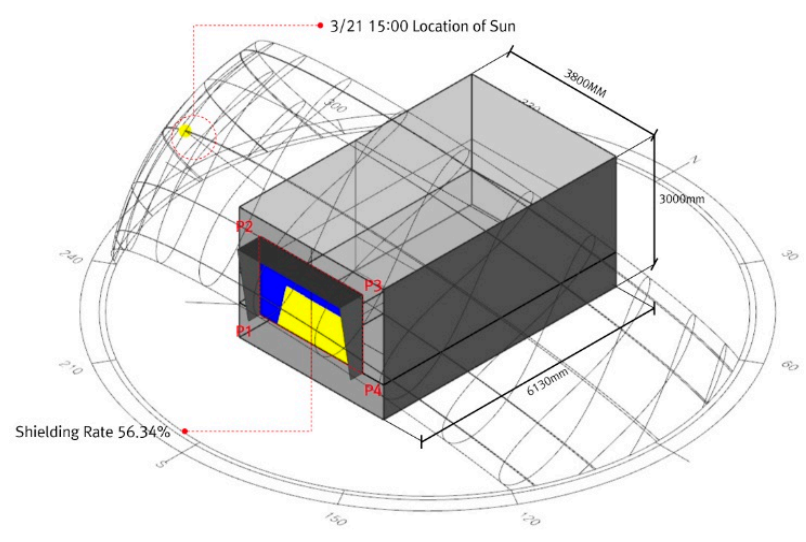

(a)

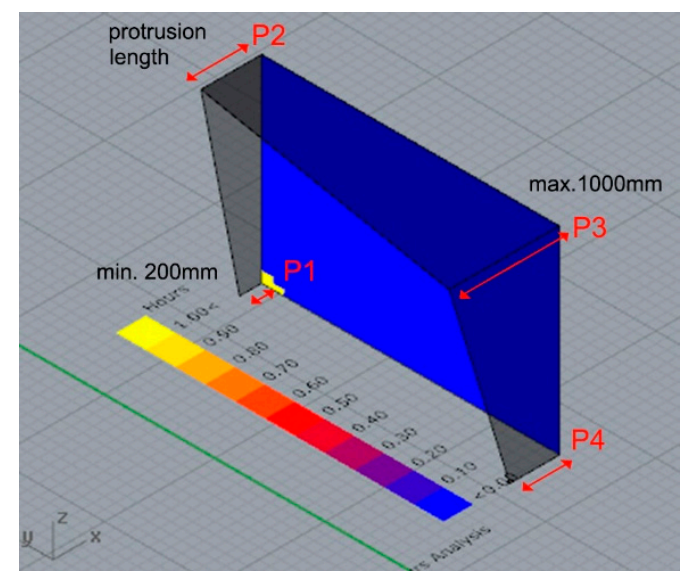

(b)

Figure 2. (a) Conceptual diagram of the movable shading device based on solar position tracking and (b) four-axis surround-type shade showing protrusion length.

These shading devices are designed to adjust the length of each axis (P1, P2, P3, and P4) accordingly in order to maximize the advantages of existing fixed overhangs, fins, and egg crates, and to compensate for the disadvantages of over shading. This is designed to improve not only the thermal performance but also the light environment performance according to the passage of time. The shading device has a default value of $200 \mathrm{~mm}$, and the length can be increased to $1000 \mathrm{~mm}$ in consideration of structural integrity and visual openness. The various shapes of shade, changing every hour according to the trajectory of the sun, were derived for business hours from 8:00 to 18:00, given that the subject buildings are intended for commercial and business usage. The minimum change in protrusion length is set at $50 \mathrm{~mm}$ in order to reflect changes in the trajectory of the sun as much as possible. This study generated different forms of shade for every hour on the summer and winter solstices, especially for south- and east-facing windows and evaluated their effectiveness on the improvement of environmental performance.

\subsubsection{Simulation Conditions}

This study is conducted to evaluate the performance of thermal and light environments according to the application of shade to medium-sized commercial or business facility buildings. In order to analyze performance by simulation, eight-floor commercial buildings were modeled with punched-type windows (window size $2700 \times 1800 \mathrm{~mm}$ ). The prototype building, plan, and window information designed for simulation analysis are shown in Figure 3.

Common conditions for thermal and light environment analysis include local location (assumed as the source considering the geographical location of the building located to conduct the study), climate, building orientation, details of the building walls, window information (window size, U-value, SHGC, and VT), and shade information including the fabric material (transmittance of the shade and fabric material, reflectance, and absorption rate). Table 1 shows the simulation analysis conditions set in this study. 


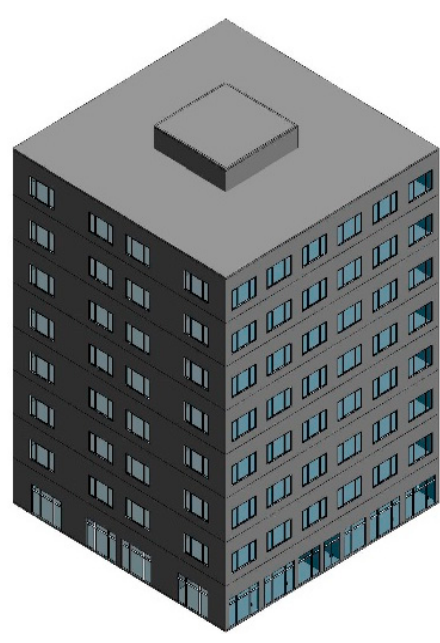

(a)

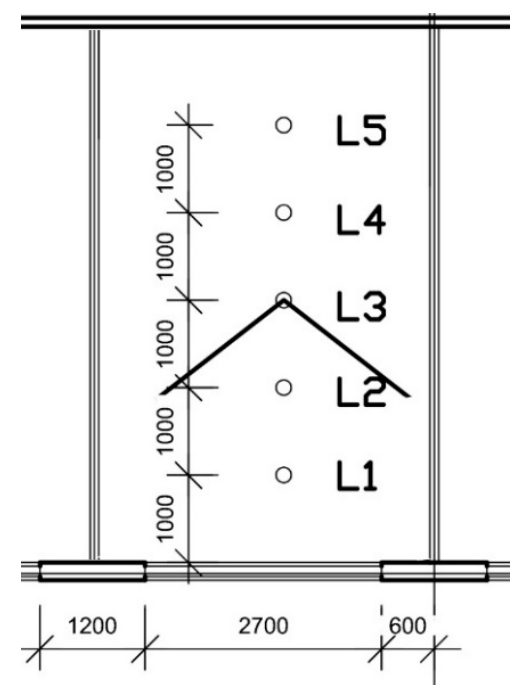

(b)

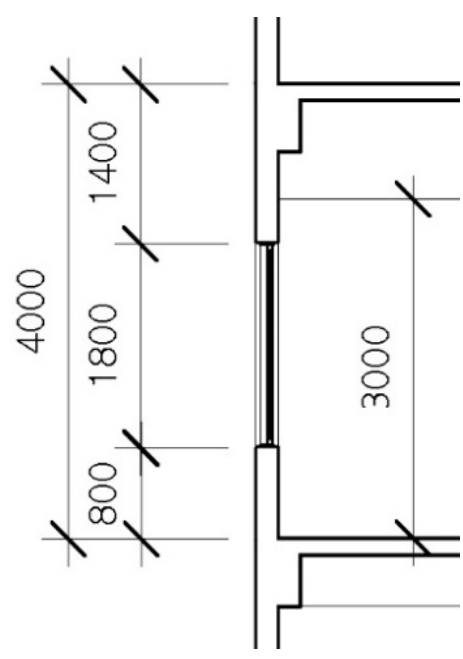

(c)

Figure 3. (a) Axonometric view of the prototype building, (b) plan view of simulated room showing illumination and daylight glare probability (DGP) measurement locations (work plane $\mathrm{H}=800$ ), and (c) section of a typical floor.

Table 1. Summary of modeling conditions for the simulation.

\begin{tabular}{|c|c|c|}
\hline Category & Information & \\
\hline Location & City & $\begin{array}{c}\text { Seoul, South Korea } \\
\left(37^{\circ} 34^{\prime} \mathrm{N}, 126^{\circ} 57^{\prime} \mathrm{E}, 87 \mathrm{~m}\right) \\
\text { Climate Type } 4 \text { (ASHRAE) }\end{array}$ \\
\hline \multirow{9}{*}{$\begin{array}{l}\text { Window size and } \\
\text { shading device }\end{array}$} & Glazed face orientation & South, East \\
\hline & Window height (mm) & 1800 \\
\hline & Window width $(\mathrm{mm})$ & 2700 \\
\hline & Maximum/minimum protrusion length (mm) & $1000 / 200$ \\
\hline & Reflectance of fabric $(\%)$ & 80 \\
\hline & Transmittance of fabric (\%) & 20 \\
\hline & Elasticity of fabric $(\%)$ & 20 \\
\hline & RGB of fabric & 0.2 \\
\hline & RGB & 0.18 \\
\hline \multirow{2}{*}{ Floor } & R-value $\left(\mathrm{W} / \mathrm{m}^{2} \mathrm{~K}\right)$ & 3.448 \\
\hline & RGB & 0.85 \\
\hline \multirow{2}{*}{ Wall } & R-value $\left(\mathrm{W} / \mathrm{m}^{2} \mathrm{~K}\right)$ & 3.703 \\
\hline & RGB & 0.6 \\
\hline \multirow{4}{*}{$\begin{array}{l}\text { Window (clear, double } \\
\text { glazed) }\end{array}$} & U-value $\left(\mathrm{Wm}^{-2} \mathrm{~K}^{-1}\right)$ & 1.17 \\
\hline & SHGC & 0.81 \\
\hline & VT & 0.647 \\
\hline & RGB & 0.86 \\
\hline \multirow{2}{*}{ Roof } & R-value $\left(\mathrm{W} / \mathrm{m}^{2} \mathrm{~K}\right)$ & 5.555 \\
\hline & Work plane & $800(\mathrm{H})$ \\
\hline \multirow{2}{*}{ Daylighting } & Illuminance measurement point & L1-L5 (Figure 3) \\
\hline & DGP measurement point & L3 (Figure 3) \\
\hline
\end{tabular}

\subsubsection{Basic Design Rule Applied to the Shading Device}

In order to calculate the optimal length of the four-axis movable shading system using the Grasshopper-Ladybug-Octopus tool in this study, P1 to P4 in Figure 2 should be specified as a variable to allow the minimum protrusion length to be adjusted by $50 \mathrm{~mm}$, respectively. As the shape of shade can change by date and time based on the connection with the EnergyPlus Weather File (EPW), 
a shielding area created by window shadow and the direct solar radiation reaching the relevant window were calculated. For the indoor light environment, illuminance, and DGP were determined.

In cases where no priority is defined between window points with regards to the generation of a shading system in an algorithm, various forms of shading devices can be randomly generated through the parametric algorithm. Thus, it is necessary to define separate design rules in order to create its shape in a more rational method. Since there exists a point that is most effective in making a shadow according to the position of the sun, an algorithm is constructed by assigning priority to each point in generating a shading system that satisfies a specific shielding rate for summer and prevents glare during winter.

First, to define design rules, a basic simulation was conducted to examine the effectiveness of vertical and horizontal elements. In summer when shielding direct solar radiation is important, horizontal elements were more effective since the window, as a subject of this study, is longer horizontally than vertically and the altitude of the sun is higher. The vertical elements, which serve a supplementary role, can help reduce the protrusion length of horizontal elements, whose effect had a positive correlation with the azimuth angle of the sun from the vertical line of the window (normal line). For example, the vertical elements demonstrated increased effect before 8:00 and after 18:00, when the incident angle was low toward the south.

With regards to the DGP, it was confirmed that there was no more benefit in P1 protruding as compared with P2 or in P4 as compared with P3. Therefore, when setting design rules, it is more reasonable to determine the $\mathrm{P} 2$ or $\mathrm{P} 3$ length first to correspond to the position of the sun, followed by the P1 or P2 length as dependent variables, and that the P1 or P4 length should not exceed that of P2 or P3, respectively. This indicates that determining the P2 or P3 length first was effective in creating a shadow and the priority between P2 and P3 can be decided depending on the solar azimuth angle.

Therefore, if the sun is on the right side of the line connecting north and south, the driving order is set to be P3 (first) $\rightarrow$ P2, P4 (second, simultaneous operation) $\rightarrow$ P1 (third). Conversely, when the sun is on the left side of the line connecting north and south, the protruding length is determined in the order of P2 (first) $\rightarrow$ P3, P1 (second, simultaneous operation) $\rightarrow$ P4 (third). In addition, the P1 length is defined to be shorter than P2, and the P4 length is defined to be shorter than P3. The maximum displacement between points was set to $400 \mathrm{~mm}$ considering the elongation of the shim material $(20 \%)$.

\subsection{Environmental Conditions and Performance Criteria Setup}

\subsubsection{Climate Condition and Basic Test for Daylight Environment}

Seoul has a humid continental climate with severe, dry winters, hot summers, and strong seasonality. The annual average temperature is $12.5^{\circ} \mathrm{C}$, the coldest month is January with a monthly average temperature of $-2.4{ }^{\circ} \mathrm{C}$, and the warmest month is August with a monthly average temperature of $25.7^{\circ}$. The annual average wind velocity is $2.3 \mathrm{~m} / \mathrm{s}$, while the annual average relative humidity is $64 \%$. High levels of solar radiation during the wintertime indicate high potential for passive solar heating. Thus, in Seoul, the subject area of this study, the reduction of cooling load is important in summer. In winter, there is no particular optimal shade in terms of heat gain; however, it is necessary to confirm whether a shade is required to control the indoor light environment.

With the aim to identify the period when the light environment becomes an issue, a Ladybug simulation was conducted to roughly identify the section where glare occurs in the indoor light environment throughout the year. Figures 4 and 5 show the simulation results. With the standard value of DGP set at 0.35 or less to prevent visual discomfort, daylight glare can be problematic in the south throughout the year, except for the period from May to August. The glare lasted continuously from an hour after sunrise to an hour before sunset, rather than being focused within a specific period. The east-facing windows can experience glare in the morning, leading to extreme visual discomfort, especially between 9:00 and 11:00 from February to March and from October to November, and between 6:00 to 7:00 from May to June. Therefore, this confirmed the necessity of shade to control the indoor light 
environment in Seoul despite some degree of deterioration in passive solar heating performance during the heating season, although the degree of glare varied depending on the orientation of windows.

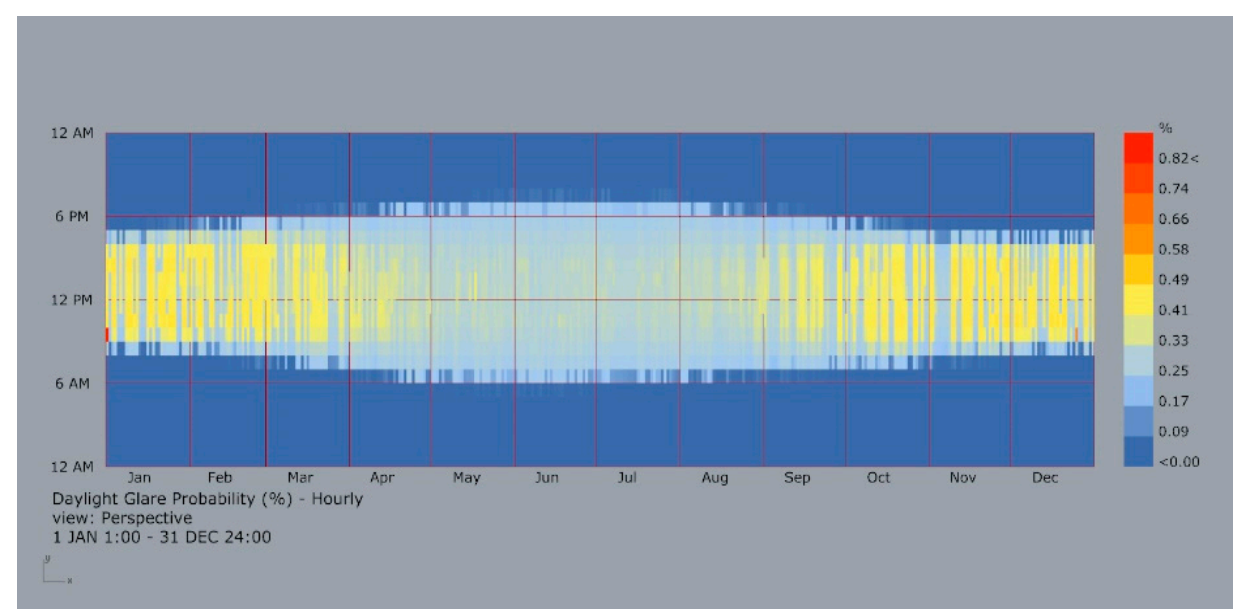

Figure 4. Annual daylight glare probability analysis (south-facing window).

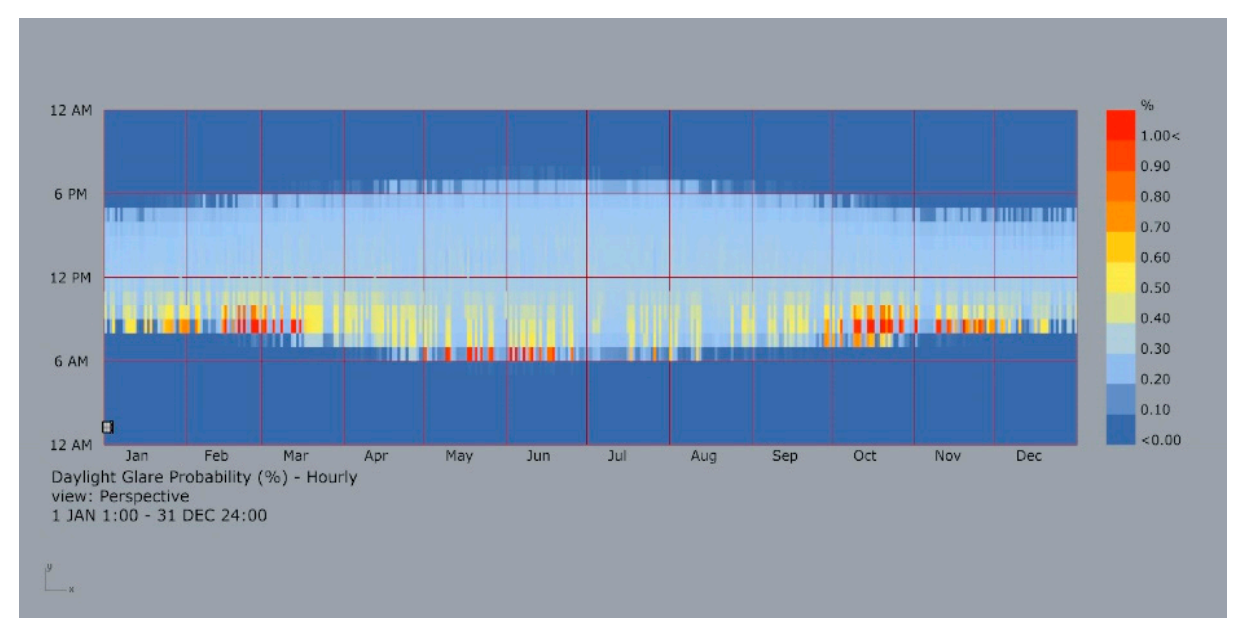

Figure 5. Annual daylight glare probability analysis (east-facing window).

\subsubsection{Performance Criteria Setup}

Controlling the thermal environment using a shading device generally aims to prevent overheating and reduce the cooling load, while the purpose of the light environment is to avoid glare and ensure proper illuminance. In order to determine the optimal shape of the movable shading device to be able to adjust to the sun's trajectory on an hourly basis, it is necessary to determine which element is given priority between thermal and light environments according to the season, orientation, and time of the day, as seen in the results of basic tests discussed in Section 2.3.1. In addition, specific indicators must be selected to evaluate the thermal and light environments.

With regards to the thermal environment, the study evaluated changes of solar radiation reaching the windows. Ultimately, it is significant to measure the extent of cooling load reduction and heating load increase depending on the shape of shade. However, the Honeybee tool, which can be linked with a parametric design tool, has the limitation of being unable to accurately reflect changes in cooling load depending on shade. There was another problem; the shape of shade changed every hour, while the heating or cooling load is calculated on a daily basis in consideration of indoor and outdoor temperatures and material properties. In contrast, solar radiation has some advantages as it strictly affects both thermal and light environments and its change can be easily measured every hour due to the shadow made according to the shape of shade. 
With regards to controlling the light environment, the DGP was measured to identify the potential occurrence of glare, which causes visual discomfort, and thus the DGP of 0.35 or less was set as the target for visual comfort. Other important factors include the reduction of the lighting load, along with the reduction of cooling load to achieve energy saving in general. However, the lighting load is a matter to be considered after first satisfying the conditions for glare prevention, because glare can be controlled only through a shade, whereas the target illuminance can be achieved with artificial lighting sources. In addition, illuminance was calculated to determine the extent of change in the value of illuminance depending on the specific form of shade and to examine whether a shading device contributes to achieving uniform illuminance.

Lastly, the solar shielding rate was determined to understand its relationship with solar radiation and DGP. Generally, a shading device with the solar shielding rate of $100 \%$ is the most effective for reducing the cooling load, while a shade with the minimum protrusion length is effective for preventing glare in winter. Thus, this paper sought to review the approximated value as to how much shielding should be achieved and examine whether there are any limitations due to the maximum protrusion length of $1000 \mathrm{~mm}$ set for structural safety.

\section{Results}

\subsection{Parametric Design Tool and Design Process}

The parametric tool for movable shade shape generation uses the algorithm necessary for environmental performance evaluation in conjunction with the Grasshopper program with the Ladybug-Octopus plug-in. Environmental performance is evaluated at the same time as the form generation, and the result can be visually plotted by the Octopus program to indicate three or more performance criteria.

In this study, the various shapes of the shade, made using the parametric design rules described in Section 2.2.3, were derived each hour, and the evaluation results of three environmental performance criteria consisting of direct radiation, DGP, and shielding rate on windows were compared using the Octopus program. Octopus was originally developed for multi-objective evolutionary optimization. It allows a search to be conducted for many goals at once, producing a range of optimized trade-off solutions between the extremes of each goal. Its usage and functions are similar to David Rutten's Galapagos, but it introduces the Pareto principle for multiple goals. While Galapagos can only derive a shape for one target value, Octopus is suitable for simultaneously comparing and evaluating the results of light and thermal environmental simulations such as movable shade in terms of expressing multiple targets simultaneously.

Figure 6 presents the entire process of generating shading shapes and algorithm composition for environmental performance evaluation. This largely consists of the following five components: First, setting up the location, date, time of the day, and orientation of the building; second, defining parametric design rules used to create the form of the shading device; third, inputting materials and their properties and locating the points for various data measurement, which is directly related to environmental performance; fourth, calculating performance criteria including solar radiation, shielding rate, and DGP; and fifth, portraying the final results in three dimensions by combining the shading shapes created and the outcome values of environmental performance and comparing them.

The Octopus algorithm is capable of not only portraying multidimensional data, but also visually plotting the results in three dimensions, as seen in Figure 7, which allows the selection of a top group of shading shapes closer to the optimal shade. However, to ensure readability and accurate data comparison, a separate sorting and selection algorithm was constructed, as shown in Figures 8 and 9 , in order to compare the generated shapes of shade and the outcome values of environmental performance based on selection criteria to derive the optimal shape by date and time of the day. 


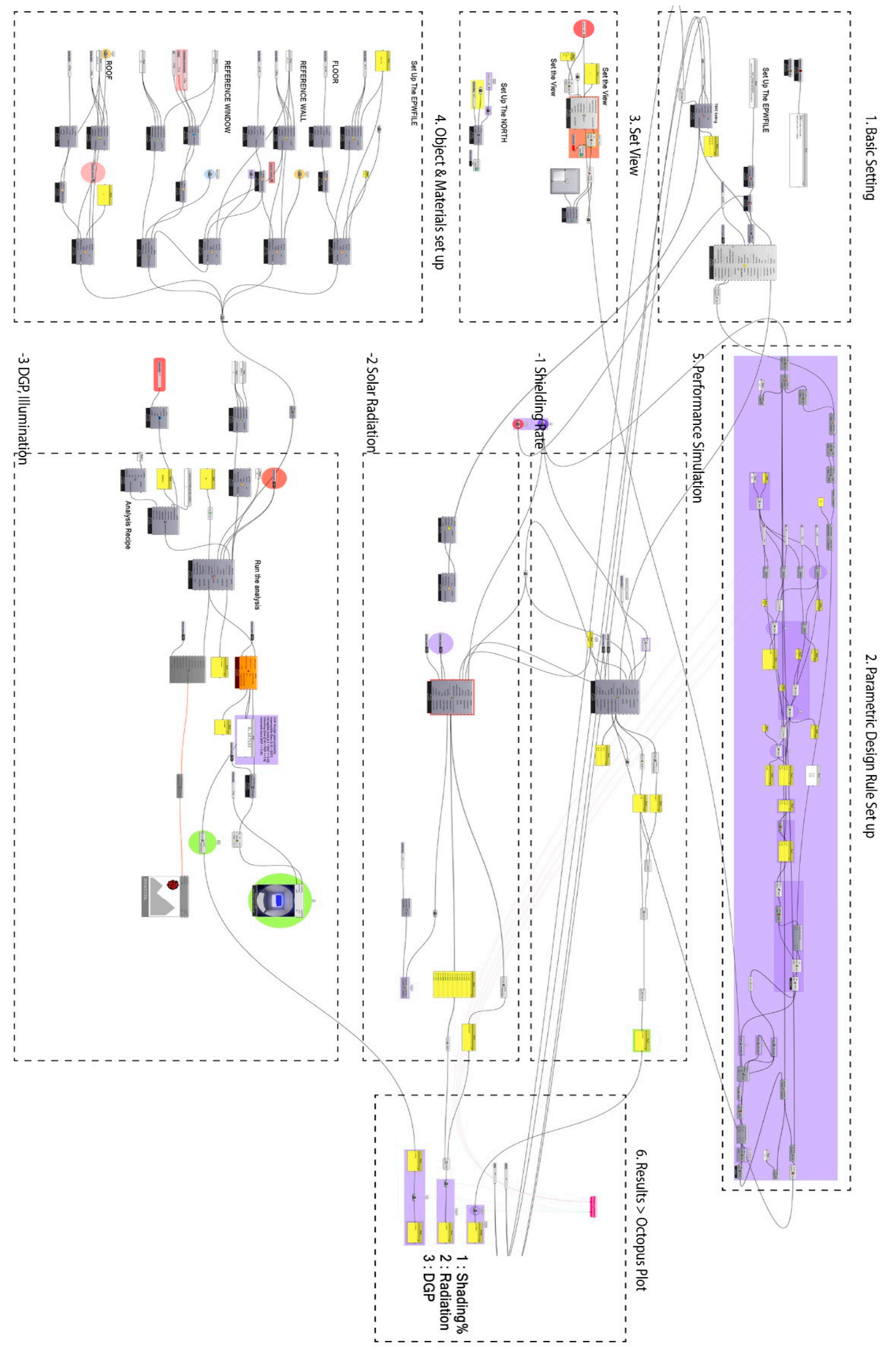

Figure 6. Overall structure of genetic algorithms for movable shade with real-time performance evaluation. 


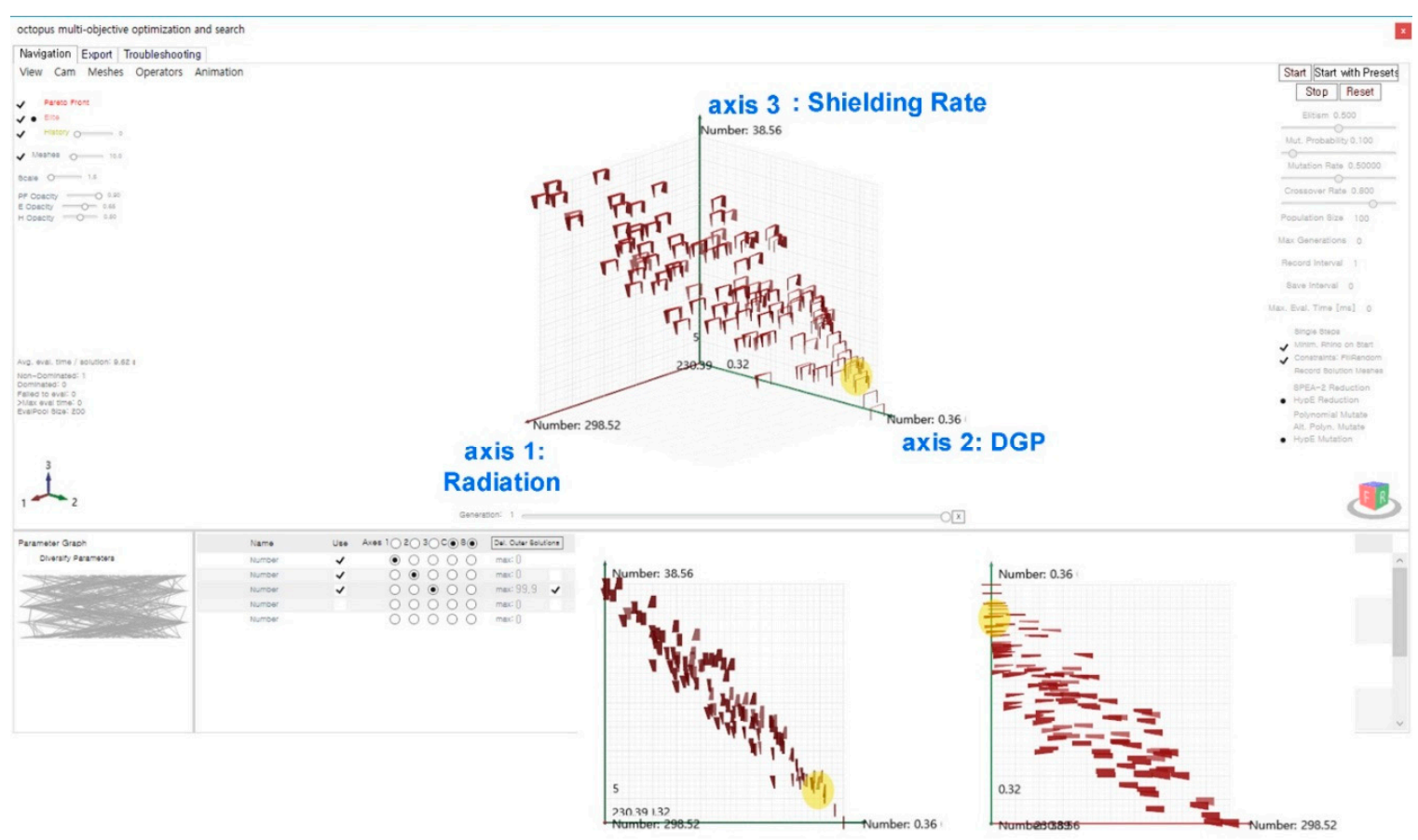

Figure 7. Example of generated forms in Octopus showing three performance criteria (yellow, possible optimized solutions satisfying DGP under 0.35 in the case of winter solstice).

S June. 21. 13:00

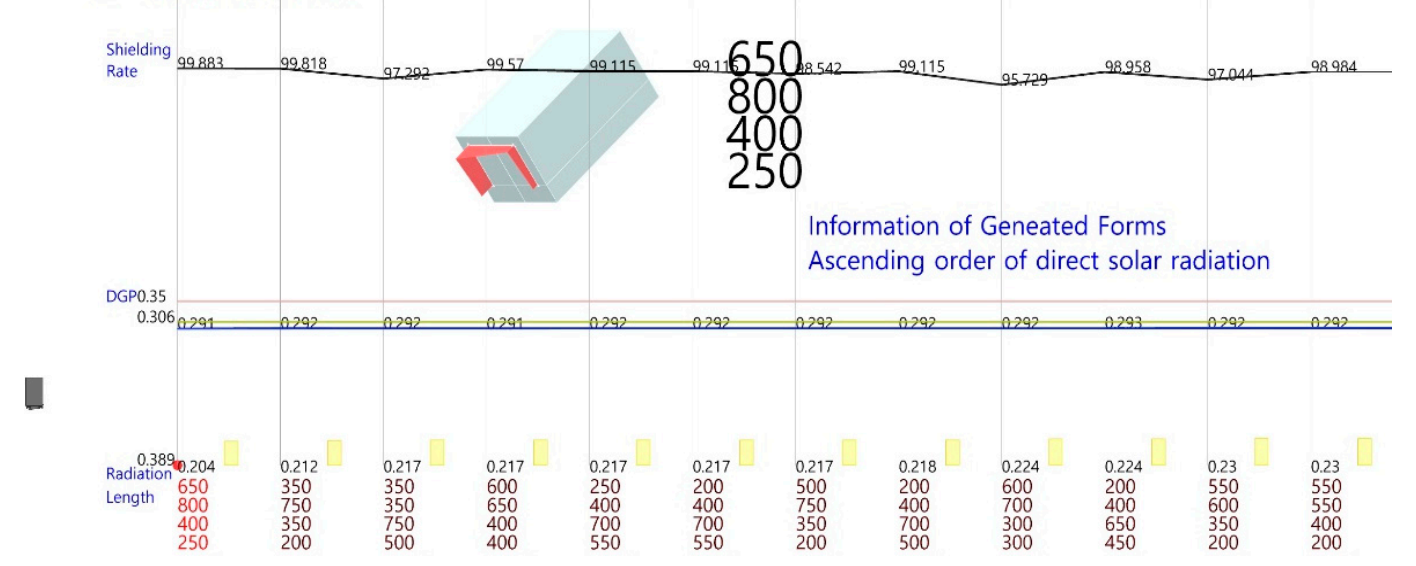

Figure 8. Example of generated forms sorted and filtered (June 21, 13:00, south-facing window).

\subsection{Example of Generated Forms and Performance Evaluation}

In order to facilitate the comparison of the final result values, a separate algorithm, such as the driving screen in Figures 8 and 9, is constructed to sequentially list the shapes that are closest to the target value. This algorithm conducted a primary selection of shapes that satisfy the DGP value of 0.35 or less among those shapes generated by genetic algorithms and, then, sorted the selected shapes in the order of least to most solar radiation in the cooling season and most to least solar radiation in the heating season. In cases where the values of solar radiation were identical, the priority was given to a shorter protrusion length. As demonstrated by the sorting results in Figures 8 and 9 , the values of solar radiation are inversely correlated with the values of shielding rate in general. However, due to the differences in the area of shadow created by each shade, the comparison of two different shapes of shade resulted in rare cases in which a form of shade with lower solar radiation shows a lower shielding rate by a narrow margin or a shade shape with higher solar ration shows a higher shielding rate. 
December. 21. 13:00

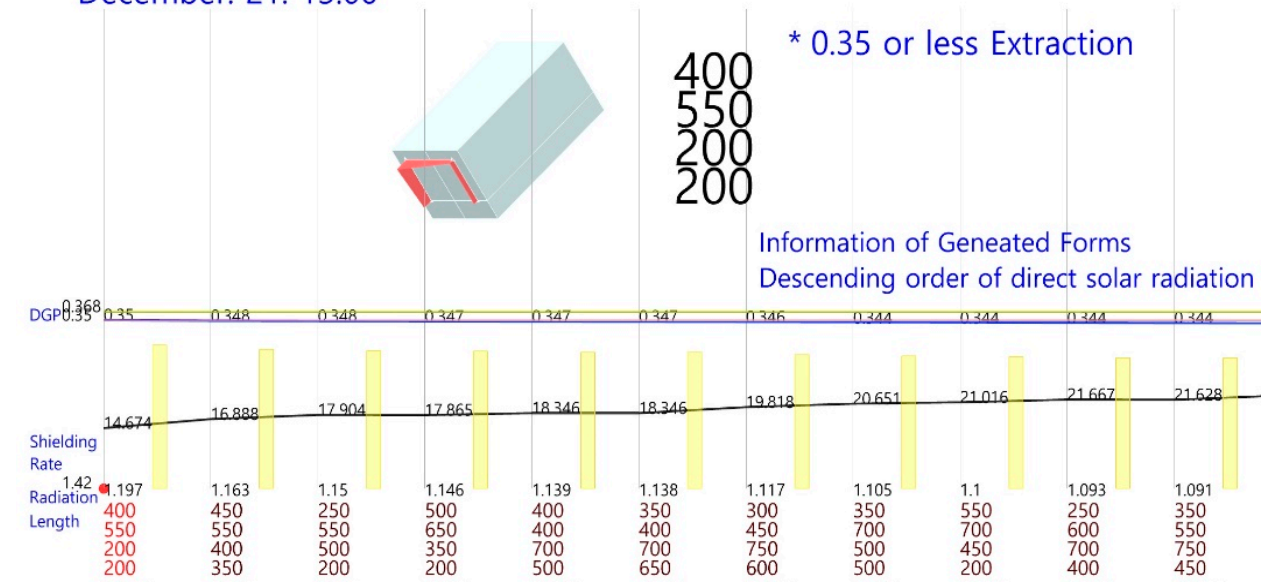

Figure 9. Example of generated forms sorted and filtered (December 21, 13:00, south-facing window).

The example shown in Figure 8 is the plotted bar chart of the shading device created for June 21, 13:00, for south-facing window, showing information such as protrusion length and various performance criteria such as solar radiation, DGP, and shielding rate. Using the developed four-axis movable shading device, the shade form was calculated from 8:00 to 18:00 on the summer and winter solstices. In the case of the summer solstice, the direct solar radiation reduction effect improved the closer it was to the solar shielding rate of $100 \%$. As shown in Figure 8, the protrusion lengths of the shade with the lowest solar radiation are set to 650, 800, 400, and 250 in the order of P1 through P4, showing the solar shielding rate of $99.88 \%$.

However, in the case of 13:00 on the winter solstice, the smaller the solar shielding rate, the smaller the decrease in the solar radiation, which is important for heat gain in winter. With regard to the solar radiation, no shade is necessary for winter; however, in order to solve the problem of glare, a shade is required. As shown in Figure 9, The protruding length of the shade with the lowest solar radiation reduction among the shapes that satisfy the DGP of 0.35 or less are set to 400, 550, 200, and 200 in the order of P1 through P4 in the case of December 21, 13:00, for south-facing window.

In this paper, the shape of the appropriate shading device was selected and its effect was verified using the highest and lowest solar altitudes as case studies. On the one hand, the study confirmed the effectiveness of selecting the shape of the four-axis movable shading device with the shortest protrusion length in summer and low total solar transmittance. On the other hand, in winter, it is important to ensure solar radiation to reduce the heating load. In this case, the optimal form to improve the visual environment could also be derived. This constitutes further proof that the point of screening can be changed according to the season and time of the day. It is apparent that the reduction of cooling load in summer and the control of light environment in winter are the highest priorities.

\subsection{Appropriate Shapes of Shade According to Changes in Time}

Tables 2 and 3 show the results of simulation for four possible cases of selected shapes among the movable shades generated. These four examples organize the appropriate shapes of shade and outcome values of the data for south- and east-facing windows, respectively, in the winter and summer solstices. The table presents the protrusion length for each point of P1 to P4, shielding rate, radiation, DGP, and illuminance, along with corresponding values for cases with no shade to be used in comparisons. The sun shade is assumed to be the default length of $200 \mathrm{~mm}$ if there is no direct sunlight on the windows or when $100 \%$ shielding can be made with the default $200 \mathrm{~mm}$ protrusion length in summer. In the case of winter, the shade length was set to the minimum length for heat gain, unless there was a problem with daylight glare. Table 4 shows the data values when there is no shade. 
Table 2. Possible optimized shade (south- facing window).

\begin{tabular}{|c|c|c|c|c|c|c|c|c|c|c|c|c|c|}
\hline South & & Time & 8 & 9 & 10 & 11 & 12 & 13 & 14 & 15 & 16 & 17 & 18 \\
\hline & & Shape & & & & & & & & & & & \\
\hline \multirow{15}{*}{$\begin{array}{c}\text { Summer Solstice } \\
(6 / 21)\end{array}$} & No Shade & $\begin{array}{c}\text { Radiation }\left(\mathrm{kWh} / \mathrm{m}^{2}\right) \\
\text { DGP }\end{array}$ & $\begin{array}{l}0.174 \\
0.257\end{array}$ & $\begin{array}{l}0.241 \\
0.271\end{array}$ & $\begin{array}{l}0.277 \\
0.283\end{array}$ & $\begin{array}{l}0.290 \\
0.293\end{array}$ & $\begin{array}{l}0.329 \\
0.304\end{array}$ & $\begin{array}{l}0.389 \\
0.306\end{array}$ & $\begin{array}{l}0.409 \\
0.294\end{array}$ & $\begin{array}{l}0.372 \\
0.285\end{array}$ & $\begin{array}{l}0.290 \\
0.274\end{array}$ & $\begin{array}{l}0.211 \\
0.260\end{array}$ & $\begin{array}{l}0.133 \\
0.244\end{array}$ \\
\hline & \multirow{14}{*}{$\begin{array}{l}\text { Movable } \\
\text { Shade }\end{array}$} & p1 (Length) & 200 & 200 & 200 & 200 & 200 & 650 & 350 & 250 & 200 & 200 & 200 \\
\hline & & p2 (Length) & 200 & 200 & 250 & 300 & 400 & 800 & 650 & 450 & 200 & 200 & 200 \\
\hline & & p3 (Length) & 200 & 250 & 500 & 600 & 600 & 400 & 350 & 250 & 200 & 200 & 200 \\
\hline & & p4 (Length) & 200 & 200 & 350 & 200 & 500 & 250 & 200 & 200 & 200 & 200 & 200 \\
\hline & & Radiation $\left(\mathrm{kWh} / \mathrm{m}^{2}\right)$ & 0.142 & 0.208 & 0.195 & 0.195 & 0.205 & 0.185 & 0.234 & 0.245 & 0.223 & 0.17 & 0.109 \\
\hline & & & 0.255 & 0.268 & 0.276 & 0.284 & 0.291 & 0.291 & 0.284 & 0.278 & 0.27 & 0.257 & 0.244 \\
\hline & & Shielding Rate (\%) & 100 & 98.11 & 99.72 & 95.21 & 98.93 & 99.88 & 98.66 & 97.77 & 100 & 100 & 100 \\
\hline & & L1 (Illuminance) & 1040 & 1622 & 1827 & 1952 & 1682 & 1910 & 2218 & 2298 & 2170 & 1668 & 1263 \\
\hline & & L2 (Illumination) & 438 & 660 & 738 & 785 & 707 & 804 & 884 & 897 & 896 & 723 & 566 \\
\hline & & L3 (Illuminance) & 204 & 324 & 340 & 365 & 340 & 383 & 428 & 436 & 426 & 352 & 279 \\
\hline & & L4 (Illuminance) & 127 & 185 & 207 & 227 & 207 & 223 & 257 & 264 & 263 & 220 & 176 \\
\hline & & L5 (llluminance) & 97 & 157 & 167 & 175 & 171 & 185 & 210 & 218 & 199 & 169 & 136 \\
\hline & & Average (Lux) & 381.2 & 589.6 & 655.8 & 700.8 & 621.4 & 701 & 799.4 & 822.6 & 790.8 & 626.4 & 484 \\
\hline & & Uniformity Ratio & 0.254 & 0.266 & 0.255 & 0.250 & 0.275 & 0.264 & 0.263 & 0.265 & 0.252 & 0.270 & 0.281 \\
\hline \multicolumn{2}{|l|}{ South } & Time & 8 & 9 & 10 & 11 & 12 & 13 & 14 & 15 & 16 & 17 & 18 \\
\hline \multirow{15}{*}{$\begin{array}{c}\text { Winter Solstice } \\
\quad(12 / 21)\end{array}$} & No Shade & $\begin{array}{c}\text { Radiation }\left(\mathrm{kWh} / \mathrm{m}^{2}\right) \\
\text { DGP }\end{array}$ & $\begin{array}{l}0.016 \\
0.248\end{array}$ & $\begin{array}{l}0.210 \\
0.315\end{array}$ & $\begin{array}{l}0.610 \\
0.373\end{array}$ & $\begin{array}{l}1.054 \\
0.375\end{array}$ & $\begin{array}{l}1.369 \\
0.367\end{array}$ & $\begin{array}{l}1.420 \\
0.368\end{array}$ & $\begin{array}{l}1.191 \\
0.375\end{array}$ & $\begin{array}{l}0.831 \\
0.372\end{array}$ & $\begin{array}{l}0.400 \\
0.321\end{array}$ & $\begin{array}{l}0.072 \\
0.249\end{array}$ & \multirow{15}{*}{ NIGHT } \\
\hline & \multirow{7}{*}{$\begin{array}{l}\text { Movable } \\
\text { Shade }\end{array}$} & p1 (Length) & 200 & 200 & 250 & 300 & 200 & 400 & 200 & 450 & 200 & 200 & \\
\hline & & p2 (Length) & 200 & 200 & 450 & 300 & 200 & 550 & 600 & 750 & 200 & 200 & \\
\hline & & p3 (Length) & 200 & 200 & 800 & 650 & 600 & 200 & 350 & 650 & 200 & 200 & \\
\hline & & p4 (Length) & 200 & 200 & 600 & 400 & 500 & 200 & 300 & 500 & 200 & 200 & \\
\hline & & Radiation $\left(\mathrm{kWh} / \mathrm{m}^{2}\right)$ & 0.014 & 0.184 & 0.41 & 0.818 & 1.147 & 1.197 & 0.964 & 0.562 & 0.353 & 0.244 & \\
\hline & & DGP & 0.242 & 0.312 & 0.346 & 0.349 & 0.349 & 0.35 & 0.35 & 0.344 & 0.317 & 0.063 & \\
\hline & & Shielding Rate (\%) & 12.11 & 10.99 & 32.64 & 21.51 & 14.91 & 14.67 & 18.27 & 31.86 & 10.99 & 13.32 & \\
\hline & & L1 (Illuminance) & - & 266 & 1613 & 8846 & 17,184 & 22,281 & 19,925 & 10,690 & 3072 & 712 & \\
\hline & & L2 (Illuminance) & - & 115 & 749 & 1623 & 15,127 & 20,794 & 18,522 & 1693 & 1386 & 373 & \\
\hline & & L3 (Illumination) & - & 54 & 421 & 921 & 1311 & 1412 & 1248 & 906 & 813 & 204 & \\
\hline & & L4 (Illumination) & - & 34 & 261 & 571 & 886 & 962 & 844 & 576 & 510 & 126 & \\
\hline & & L5 (Illumination) & - & 26 & 211 & 480 & 705 & 805 & 709 & 469 & 373 & 95 & \\
\hline & & Average (Lux) & - & 99 & 651 & 2488.2 & 7042.6 & 9250.8 & 8249.6 & 2866.8 & 1230.8 & 302 & \\
\hline & & Uniformity Ratio & & 0.263 & 0.324 & 0.193 & 0.100 & 0.087 & 0.086 & 0.164 & 0.303 & 0.315 & \\
\hline
\end{tabular}


Table 3. Possible optimized shade (east-facing window).

\begin{tabular}{|c|c|c|c|c|c|c|c|c|c|c|c|c|c|}
\hline East & & Time & 8 & 9 & 10 & 11 & 12 & 13 & 14 & 15 & 16 & 17 & 18 \\
\hline \multirow{15}{*}{$\begin{array}{c}\text { Summer Solstice } \\
(6 / 21)\end{array}$} & \multirow[t]{5}{*}{ No Shade } & Radiation $\left(\mathrm{kWh} / \mathrm{m}^{2}\right)$ & 0.268 & 0.352 & 0.318 & 0.304 & 0.297 & 0.292 & 0.283 & 0.279 & 0.273 & 0.263 & 0.248 \\
\hline & & DGP & 0.368 & 0.335 & 0.328 & 0.308 & 0.294 & 0.271 & 0.245 & 0.217 & 0.182 & 0.150 & 0.105 \\
\hline & & p1 (Length) & 550 & 700 & 850 & 550 & 400 & 200 & 200 & 200 & 200 & 200 & 200 \\
\hline & & p2 (Length) & 850 & 1000 & 1000 & 800 & 500 & 200 & 200 & 200 & 200 & 200 & 200 \\
\hline & & p3 (Length) & 950 & 950 & 950 & 600 & 300 & 200 & 200 & 200 & 200 & 200 & 200 \\
\hline & \multirow{10}{*}{$\begin{array}{l}\text { Movable } \\
\text { Shade }\end{array}$} & p4 (Length) & 900 & 650 & 750 & 250 & 200 & 200 & 200 & 200 & 200 & 200 & 200 \\
\hline & & DGP & 0.334 & 0.313 & 0.297 & 0.29 & 0.288 & 0.288 & 0.28 & 0.276 & 0.269 & 0.262 & 0.251 \\
\hline & & Shielding Rate (\%) & 32.84 & 46.49 & 79.13 & 88.23 & 99.78 & 100 & 100 & 100 & 100 & 100 & 100 \\
\hline & & L1 (Illuminance) & 1122 & 1976 & 1513 & 1747 & 1932 & 2192 & 1910 & 1786 & 1545 & 1309 & 1078 \\
\hline & & L2 (Illuminance) & 643 & 685 & 614 & 753 & 803 & 882 & 791 & 803 & 713 & 617 & 511 \\
\hline & & L3 (Illuminance) & 270 & 333 & 325 & 378 & 395 & 408 & 374 & 399 & 360 & 314 & 261 \\
\hline & & L4 (Illuminance) & 147 & 223 & 215 & 221 & 218 & 235 & 219 & 241 & 219 & 193 & 160 \\
\hline & & L5 (Illuminance) & 127 & 170 & 168 & 185 & 196 & 192 & 182 & 205 & 188 & 166 & 138 \\
\hline & & Average (Lux) & 461.8 & 677.4 & 567 & 656.8 & 708.8 & 781.8 & 695.2 & 686.8 & 605 & 519.8 & 429.6 \\
\hline & & Uniformity Ratio & 0.275 & 0.251 & 0.296 & 0.282 & 0.277 & 0.246 & 0.262 & 0.298 & 0.311 & 0.319 & 0.321 \\
\hline \multicolumn{2}{|l|}{ East } & Time & 8 & 9 & 10 & 11 & 12 & 13 & 14 & 15 & 16 & 17 & 18 \\
\hline \multirow{15}{*}{$\begin{array}{c}\text { Winter Solstice } \\
(12 / 21)\end{array}$} & No Shade & $\begin{array}{c}\text { Radiation }\left(\mathrm{kWh} / \mathrm{m}^{2}\right) \\
\text { DGP }\end{array}$ & $\begin{array}{l}0.017 \\
0.269\end{array}$ & $\begin{array}{l}0.199 \\
0.313\end{array}$ & $\begin{array}{l}0.459 \\
0.369\end{array}$ & $\begin{array}{l}0.515 \\
0.308\end{array}$ & $\begin{array}{l}0.309 \\
0.273\end{array}$ & $\begin{array}{l}0.122 \\
0.255\end{array}$ & $\begin{array}{l}0.114 \\
0.251\end{array}$ & $\begin{array}{l}0.106 \\
0.244\end{array}$ & $\begin{array}{l}0.066 \\
0.228\end{array}$ & $\begin{array}{l}0.023 \\
0.215\end{array}$ & \multirow{15}{*}{ NIGHT } \\
\hline & \multirow{7}{*}{$\begin{array}{l}\text { Movable } \\
\text { Shade }\end{array}$} & $\mathrm{p} 1$ (Length) & 200 & 200 & 200 & 200 & 200 & 200 & 200 & 200 & 200 & 200 & \\
\hline & & p2 (Length) & 200 & 200 & 350 & 200 & 200 & 200 & 200 & 200 & 200 & 200 & \\
\hline & & p3 (Length) & 200 & 200 & 250 & 200 & 200 & 200 & 200 & 200 & 200 & 200 & \\
\hline & & p4 (Length) & 200 & 200 & 200 & 200 & 200 & 200 & 200 & 200 & 200 & 200 & \\
\hline & & Radiation $\left(\mathrm{kWh} / \mathrm{m}^{2}\right)$ & 0.014 & 0.173 & 0.366 & 0.394 & 0.222 & 0.1 & 0.09 & 0.09 & 0.06 & 0.02 & \\
\hline & & DGP & 0.265 & 0.304 & 0.344 & 0.29 & 0.259 & 0.254 & 0.249 & 0.244 & 0.228 & 0.213 & \\
\hline & & Shielding Rate (\%) & 4.67 & 9.19 & 19.72 & 28.1 & 71.65 & 100 & 100 & 100 & 100 & 100 & \\
\hline & & L1 (Illuminance) & - & 275 & 1786 & 2158 & 1557 & 940 & 840 & 994 & 719 & 331 & \\
\hline & & L2 (Illuminance) & - & 121 & 874 & 1031 & 726 & 461 & 421 & 482 & 359 & 171 & \\
\hline & & L3 (Illuminance) & - & 58 & 471 & 533 & 379 & 250 & 232 & 251 & 191 & 92 & \\
\hline & & L4 (Illuminance) & - & 34 & 287 & 319 & 233 & 162 & 152 & 156 & 120 & 58 & \\
\hline & & L5 (Illuminance) & - & 29 & 219 & 258 & 198 & 148 & 140 & 135 & 105 & 51 & \\
\hline & & Average (Lux) & - & 103.4 & 727.4 & 859.8 & 618.6 & 392.2 & 357 & 403.6 & 298.8 & 140.6 & \\
\hline & & Uniformity Ratio & & 0.280 & 0.301 & 0.300 & 0.320 & 0.377 & 0.392 & 0.334 & 0.351 & 0.363 & \\
\hline
\end{tabular}


Table 4. Radiation, DGP, and illumination data without shade (south- and east-facing window).

\begin{tabular}{|c|c|c|c|c|c|c|c|c|c|c|c|c|c|}
\hline South & & Time & 8 & 9 & 10 & 11 & 12 & 13 & 14 & 15 & 16 & 17 & 18 \\
\hline \multirow{9}{*}{$\begin{array}{l}\text { Summer Solstice } \\
(6 / 21)\end{array}$} & & Radiation $\left(\mathrm{kWh} / \mathrm{m}^{2}\right)$ & 0.174 & 0.241 & 0.277 & 0.290 & 0.329 & 0.389 & 0.409 & 0.372 & 0.290 & 0.211 & 0.133 \\
\hline & & DGP & 0.257 & 0.271 & 0.283 & 0.293 & 0.304 & 0.306 & 0.294 & 0.285 & 0.274 & 0.260 & 0.244 \\
\hline & & L1 (Illuminance) & 1273 & 2090 & 2675 & 3026 & 2819 & 3612 & 3812 & 3378 & 2685 & 2030 & 1520 \\
\hline & & L2 (Illuminance) & 509 & 817 & 1028 & 1154 & 1071 & 1306 & 1364 & 1243 & 1043 & 837 & 653 \\
\hline & No Shade & L3 (Illuminance) & 244 & 386 & 479 & 533 & 505 & 601 & 627 & 589 & 504 & 414 & 328 \\
\hline & & L4 (Illuminance) & 144 & 224 & 273 & 302 & 291 & 338 & 352 & 342 & 297 & 249 & 199 \\
\hline & & L5 (Illuminance) & 112 & 173 & 208 & 228 & 223 & 257 & 268 & 265 & 232 & 196 & 157 \\
\hline & & Ave. Illumination (Lx) & 456.4 & 738 & 932.6 & 1048.6 & 981.8 & 1222.8 & 1284.6 & 1163.4 & 952.2 & 745.2 & 571.4 \\
\hline & & Uniformity Ratio & 0.245 & 0.234 & 0.223 & 0.217 & 0.227 & 0.210 & 0.209 & 0.228 & 0.244 & 0.263 & 0.275 \\
\hline \multirow{9}{*}{$\begin{array}{l}\text { Winter Solstice } \\
\qquad(12 / 21)\end{array}$} & & Radiation $\left(\mathrm{kWh} / \mathrm{m}^{2}\right)$ & 0.016 & 0.210 & 0.610 & 1.054 & 1.369 & 1.420 & 1.191 & 0.831 & 0.400 & 0.072 & \\
\hline & & DGP & 0.248 & 0.315 & 0.373 & 0.375 & 0.367 & 0.368 & 0.375 & 0.372 & 0.321 & 0.249 & \\
\hline & & L1 (Illuminance) & - & 322 & 3726 & 10,322 & 18,382 & 22,960 & 20,890 & 12,596 & 6339 & 834 & \\
\hline & & L2 (Illuminance) & - & 133 & 1218 & 2493 & 16,071 & 21,440 & 19,278 & 2767 & 1591 & 429 & \\
\hline & & L3 (Illuminance) & - & 65 & 664 & 1331 & 1756 & 1756 & 1665 & 1402 & 939 & 235 & NIGHT \\
\hline & No Shade & L4 (Illuminance) & - & 38 & 407 & 829 & 1163 & 1208 & 1146 & 900 & 581 & 144 & \\
\hline & & L5 (Illuminance) & - & 30 & 309 & 645 & 906 & 982 & 925 & 692 & 443 & 108 & \\
\hline & & Ave. Illumination (Lx) & & 117.6 & 1264.8 & 3124 & 7655.6 & 9669.2 & 8780.8 & 3671.4 & 1978.6 & 350 & \\
\hline & & Uniformity Ratio & & 0.255 & 0.244 & 0.206 & 0.118 & 0.102 & 0.105 & 0.188 & 0.224 & 0.309 & \\
\hline East & & Time & 8 & 9 & 10 & 11 & 12 & 13 & 14 & 15 & 16 & 17 & 18 \\
\hline \multirow{9}{*}{$\begin{array}{l}\text { Summer Solstice } \\
\text { (6/21) }\end{array}$} & & Radiation $\left(\mathrm{kWh} / \mathrm{m}^{2}\right)$ & 0.268 & 0.352 & 0.318 & 0.304 & 0.297 & 0.292 & 0.283 & 0.279 & 0.273 & 0.263 & 0.248 \\
\hline & & DGP & 0.368 & 0.335 & 0.328 & 0.308 & 0.294 & 0.271 & 0.245 & 0.217 & 0.182 & 0.150 & 0.105 \\
\hline & & L1 (Illuminance) & 2142 & 3875 & 4065 & 3366 & 2911 & 2723 & 2353 & 2149 & 1841 & 1550 & 1274 \\
\hline & & L2 (Illuminance) & 1053 & 1401 & 1373 & 1275 & 1100 & 1014 & 906 & 911 & 807 & 696 & 577 \\
\hline & No Shade & L3 (Illuminance) & 635 & 696 & 649 & 601 & 530 & 488 & 944 & 468 & 421 & 367 & 305 \\
\hline & & L4 (Illuminance) & 222 & 329 & 321 & 297 & 269 & 249 & 233 & 257 & 234 & 206 & 171 \\
\hline & & L5 (Illuminance) & 184 & 268 & 260 & 241 & 223 & 207 & 195 & 220 & 201 & 177 & 147 \\
\hline & & Ave. Illumination (Lx) & 847.2 & 1313.8 & 1333.6 & 1156 & 1006.6 & 936.2 & 926.2 & 801 & 700.8 & 599.2 & 494.8 \\
\hline & & Uniformity Ratio & 0.217 & 0.204 & 0.195 & 0.208 & 0.222 & 0.221 & 0.211 & 0.275 & 0.287 & 0.295 & 0.297 \\
\hline \multirow{9}{*}{$\begin{array}{c}\text { Winter Solstice } \\
\quad(12 / 21)\end{array}$} & & Radiation $\left(\mathrm{kWh} / \mathrm{m}^{2}\right)$ & 0.017 & 0.199 & 0.459 & 0.515 & 0.309 & 0.122 & 0.114 & 0.106 & 0.066 & 0.023 & \\
\hline & & DGP & 0.269 & 0.313 & 0.369 & 0.308 & 0.273 & 0.255 & 0.251 & 0.244 & 0.228 & 0.215 & \\
\hline & \multirow{7}{*}{ No Shade } & L1 (Illuminance) & - & 331 & 2282 & 2649 & 1971 & 1121 & 987 & 1173 & 840 & 382 & \multirow{5}{*}{ NIGHT } \\
\hline & & L2 (Illuminance) & - & 138 & 1106 & 1221 & 887 & 526 & 475 & 544 & 404 & 191 & \\
\hline & & L3 (Illuminance) & - & 69 & 594 & 640 & 473 & 291 & 267 & 292 & 221 & 106 & \\
\hline & & L4 (Illuminance) & - & 36 & 327 & 357 & 265 & 174 & 163 & 166 & 128 & 62 & \\
\hline & & L5 (Illuminance) & - & 31 & 264 & 284 & 223 & 156 & 147 & 144 & 112 & 55 & \\
\hline & & Ave. Illumination(Lx) & - & 121 & 914.6 & 1030.2 & 763.8 & 453.6 & 407.8 & 463.8 & 341 & 159.2 & \\
\hline & & Uniformity Ratio & - & 0.256 & 0.289 & 0.276 & 0.292 & 0.344 & 0.360 & 0.310 & 0.328 & 0.345 & \\
\hline
\end{tabular}


On the summer solstice, the sunshade with the least solar radiation is optimal for reducing the cooling load, and in this case, its shielding rate approaches close to $100 \%$. There may be some shades with identical or similar solar radiation, in which case it is advantageous to select the one whose protrusion length is shorter since that gives more openness when viewed from inside. For the south-facing window on the summer solstice, solar radiation was highest from 12:00 to 15:00, and it was confirmed that solar radiation could be reduced significantly with the installation of the proposed sunshade. For example, in the case of $14: 00$, the radiation is $0.409 \mathrm{kWh} / \mathrm{m}^{2}$ when there is no shade, whereas the radiation is reduced to $0.234 \mathrm{kWh} / \mathrm{m}^{2}$ when the proposed shade is set to $350,650,350$, and 200 in order of P1 through P4. P2 or p3 had to be projected by 650 to $800 \mathrm{~mm}$ in order to create a shade close to $100 \%$ shielding from 12:00 15:00 with strong radiation. Once P2 or P3 reached a certain length, the longer length did not help to increase the shielding rate, and increasing the length of the other side approached $100 \%$ of the shielding rate. At 8:00 and after 16:00, a shielding rate of $100 \%$ was achieved with a default projecting length of $200 \mathrm{~mm}$ shades. For the south-facing window on the summer solstice, since the absence of shade does not cause any problem regarding glare, the eventual purpose of a shade is to reduce the cooling load, which signifies that a shade with a shielding rate of almost $100 \%$ is optimal.

East-facing windows were confirmed to have no problem of glare on the summer solstice because of the high altitude of the sun except at 8:00. In the case of 8:00, the DGP was changed from 0.368 to 0.334 due to the installation of the proposed shade. However, as the maximum protrusion length of a shade is $1000 \mathrm{~mm}$, its highest shielding rates from 8:00 to 10:00 are $32.84 \%, 46.49 \%$, and $79.13 \%$ for each time period, respectively. This is because there are limitations in creating shielding areas due to the azimuth at the time of sunrise. For the period from 11:00 to 12:00, it was confirmed that shapes with shielding rates of almost $100 \%$ can be generated, thereby preventing solar radiation more effectively. Meanwhile, as there is no direct solar radiation at east-facing windows after noon, shade shapes were derived only by the time when shades were meaningful.

A separate simulation shows that the shade lengths of the east-facing window at 8:00 on the summer solstice must be $1500 \mathrm{~mm}, 1950 \mathrm{~mm}, 1800 \mathrm{~mm}$, and $700 \mathrm{~mm}$ for P1, P2, P3, and P4, respectively, in order to achieve a shielding rate of $95.47 \%$. Meanwhile, the protrusion length is required to be approximately $5000 \mathrm{~mm}$ at 7:00 and $3000 \mathrm{~mm}$ at 8:00, which signifies that achieving a shielding rate of $100 \%$ is obsolete in the early morning with surround-type exterior sunshades, due to the requirement for the protrusion length not to exceed the maximum value. However, in this study, where the maximum protrusion length was set at $1000 \mathrm{~mm}$, it is meaningful that every appropriate sunshade selected for each time period of work hours from 8:00 to 12:00 satisfies the DGP limit of 0.35, and its shielding reduces direct solar radiation to some extent.

In winter, the shade with default values of 200, 200, 200, and 200 is advantageous in terms of heating load in other time periods in order to secure solar radiation. However, in the case of the result of the morphological derivation on the winter solstice for the south-facing window, from 10:00 to 15:003, the shade was required to control the indoor light environment. The shielding rate of the shade satisfying the minimum DGP ranges from $14.67 \%$ to $32.64 \%$ at the said time period. At 10:00 and 15:00, the protrusion length was the longest, reaching 750 to $800 \mathrm{~mm}$. These results show that the winter brightness problem can be solved if the shielding rate is maintained at an appropriate level. In cases where there is a problem of glare in the indoor light environment, the shade that satisfies indoor visual comfort is optimal, as it allows appropriate shapes of shade to be derived, even if the heating load increases due to a slight reduction in solar radiation. At the time when there was no glare problem, the default shade of $200 \mathrm{~mm}$ was applied, and the DGP was further improved

As glare was a problem at east-facing windows at 10:00 on the winter solstice, the issue of glare was prioritized when selecting the appropriate shade. Shielding rates derived at the time were $19.72 \%$ with the shade set of 200, 350, 250 and 200, which demonstrates that shades are necessary for controlling the light environment, although the heating load inevitably increases to some extent. The installation of the shade reduced the DGP from 0.369 to 0.344 . It was confirmed, therefore, that the algorithm 
proposed in this study makes it possible to derive the appropriate shapes of shades that are close to targets by simultaneously taking into consideration both light and thermal environments.

\section{Discussion}

\subsection{Performance Evaluation Results}

In this section, the changes in environmental performance resulting from the shapes of movable shade proposed in Chapter 3 were compared to those in the case of no shades, as a way to confirm the utility of the proposed shapes. Detailed numerical data is based on the description in Tables 2 and 4 . Figures 10-17 show the analytical results of simulations for cases of possible optimized shapes among the movable shades generated for each time period.

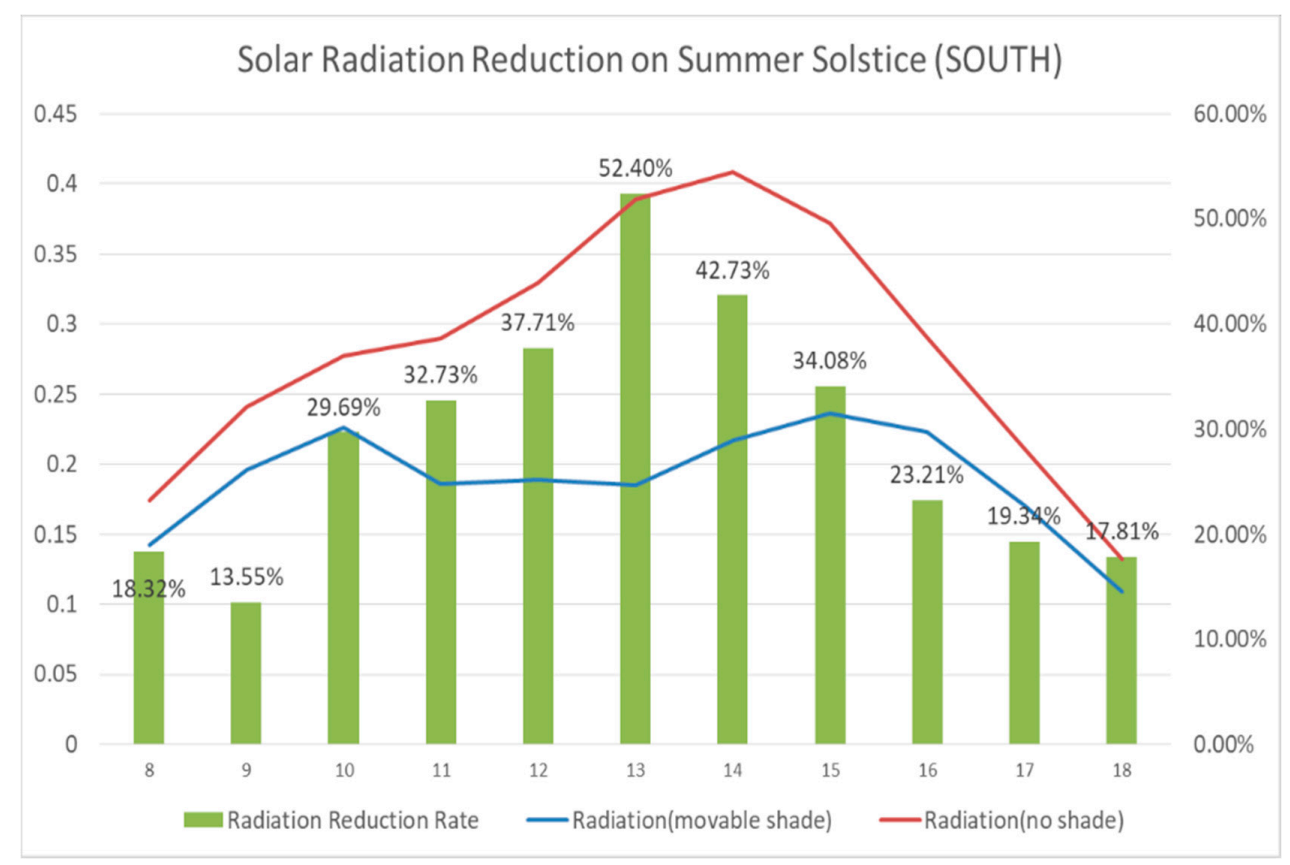

Figure 10. Solar radiation reduction on summer solstice (south-facing window).

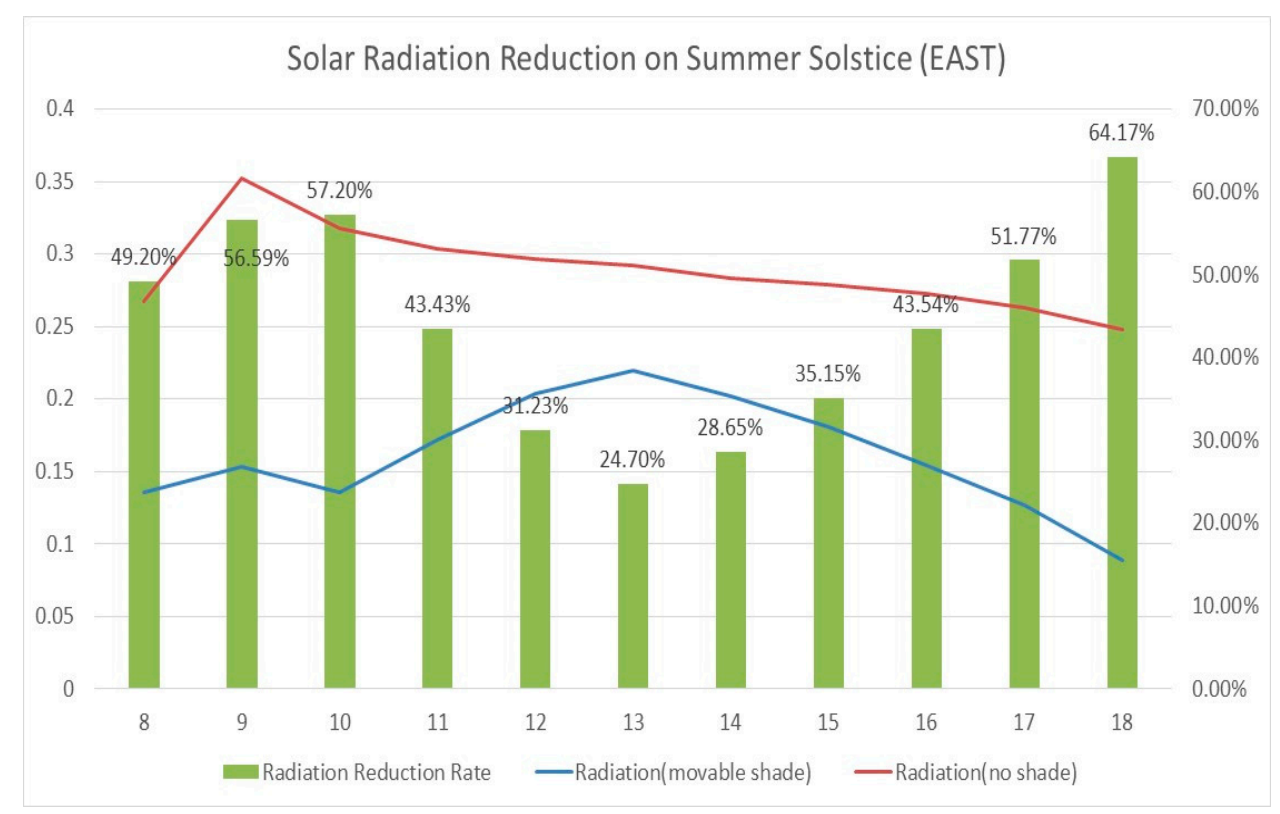

Figure 11. Solar radiation reduction on summer solstice (east-facing window). 


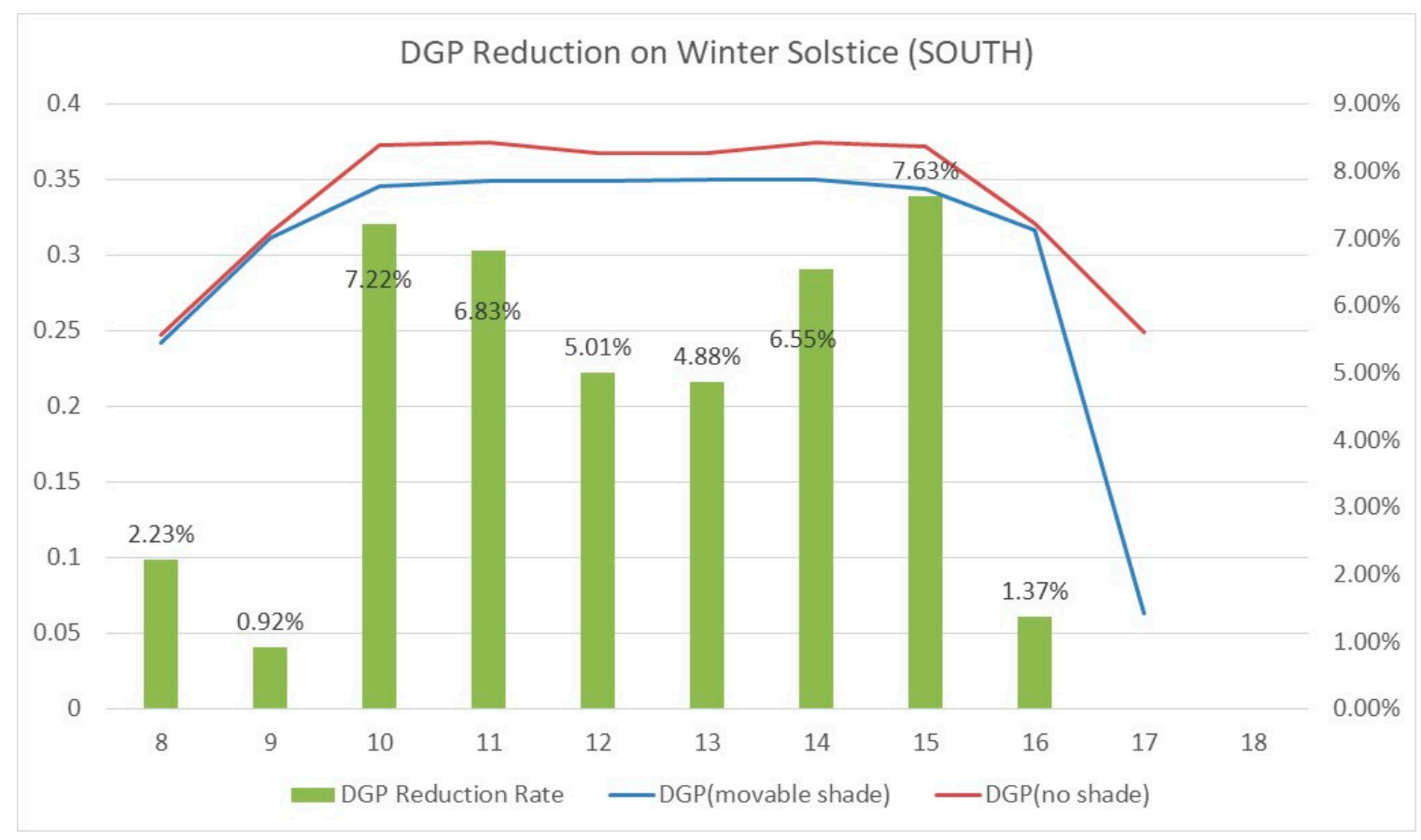

Figure 12. DGP reduction on winter solstice (south-facing window).

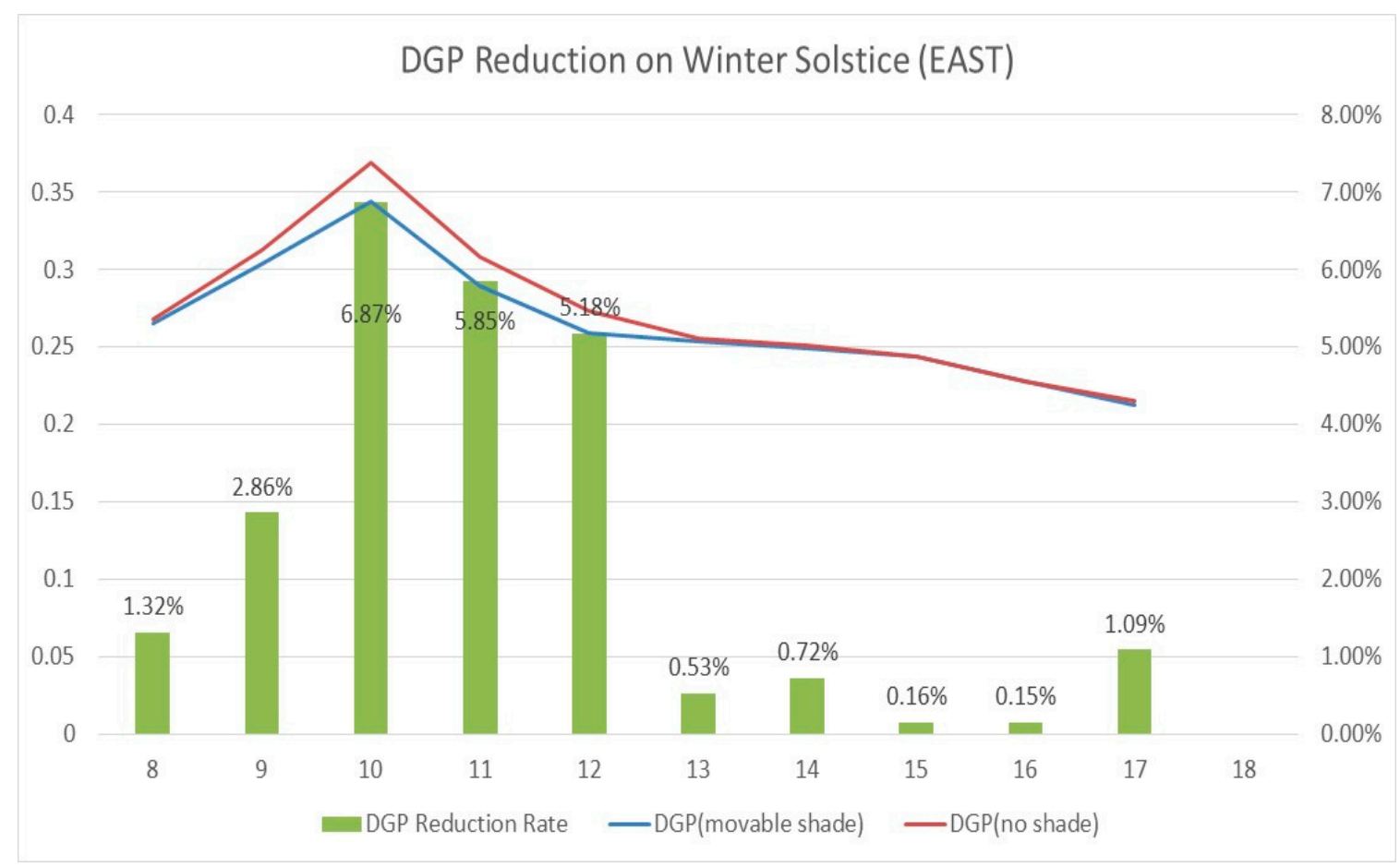

Figure 13. DGP reduction on winter solstice (east-facing window). 


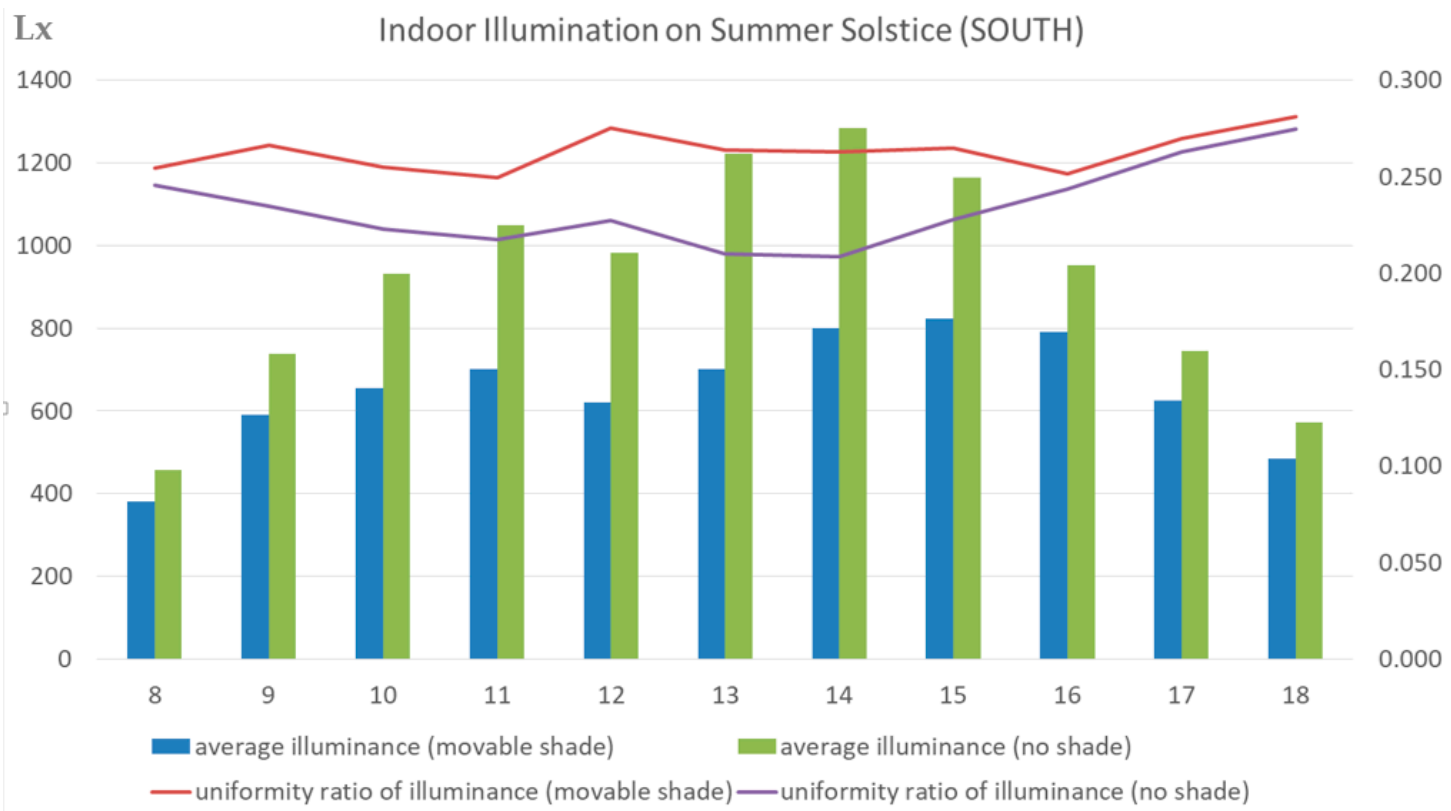

Figure 14. Indoor illumination analysis on summer solstice (south-facing window).

Lx Indoor Illumination on Winter Solstice (SOUTH)

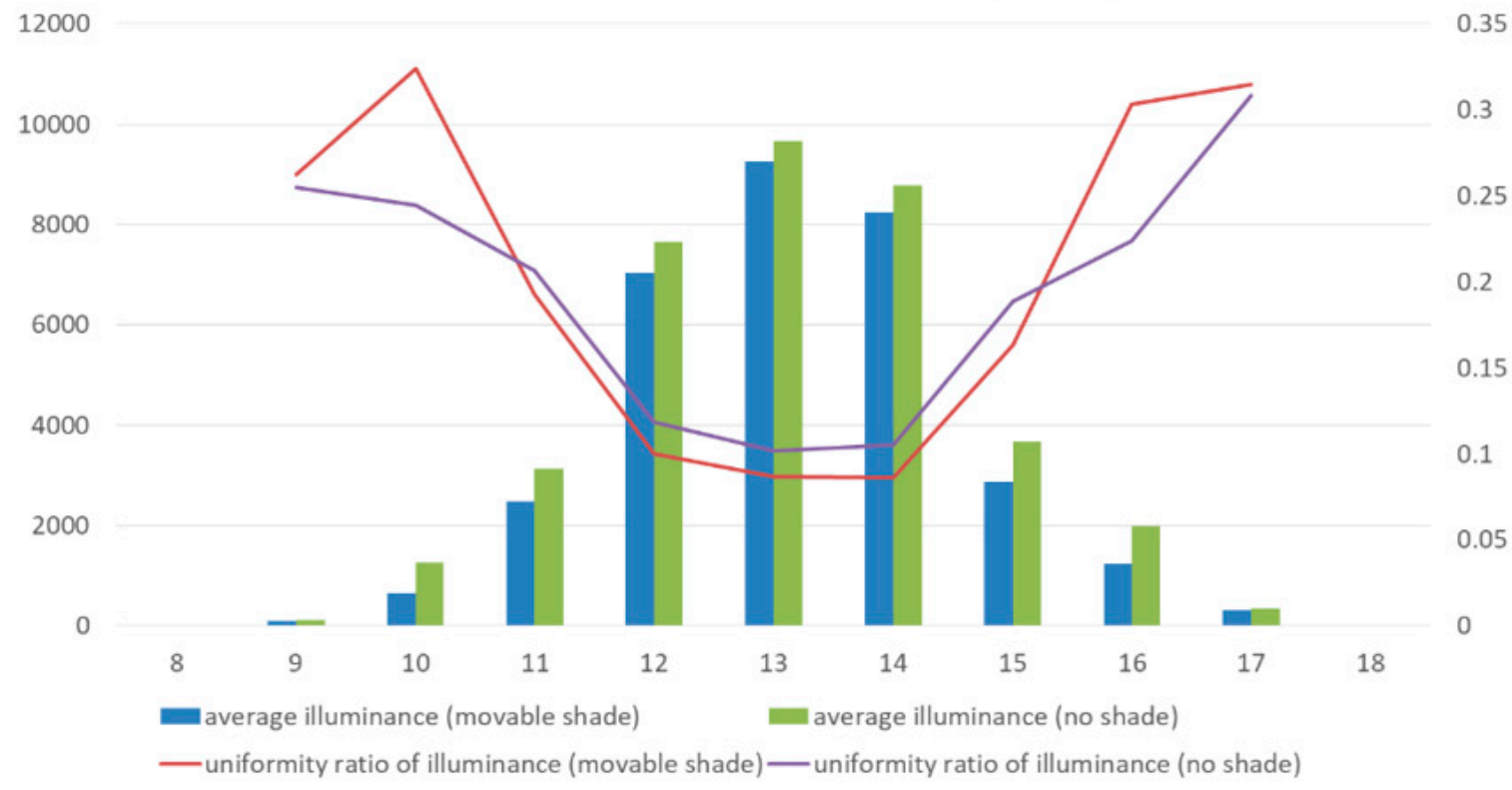

Figure 15. Indoor illumination analysis on winter solstice south-facing window). 


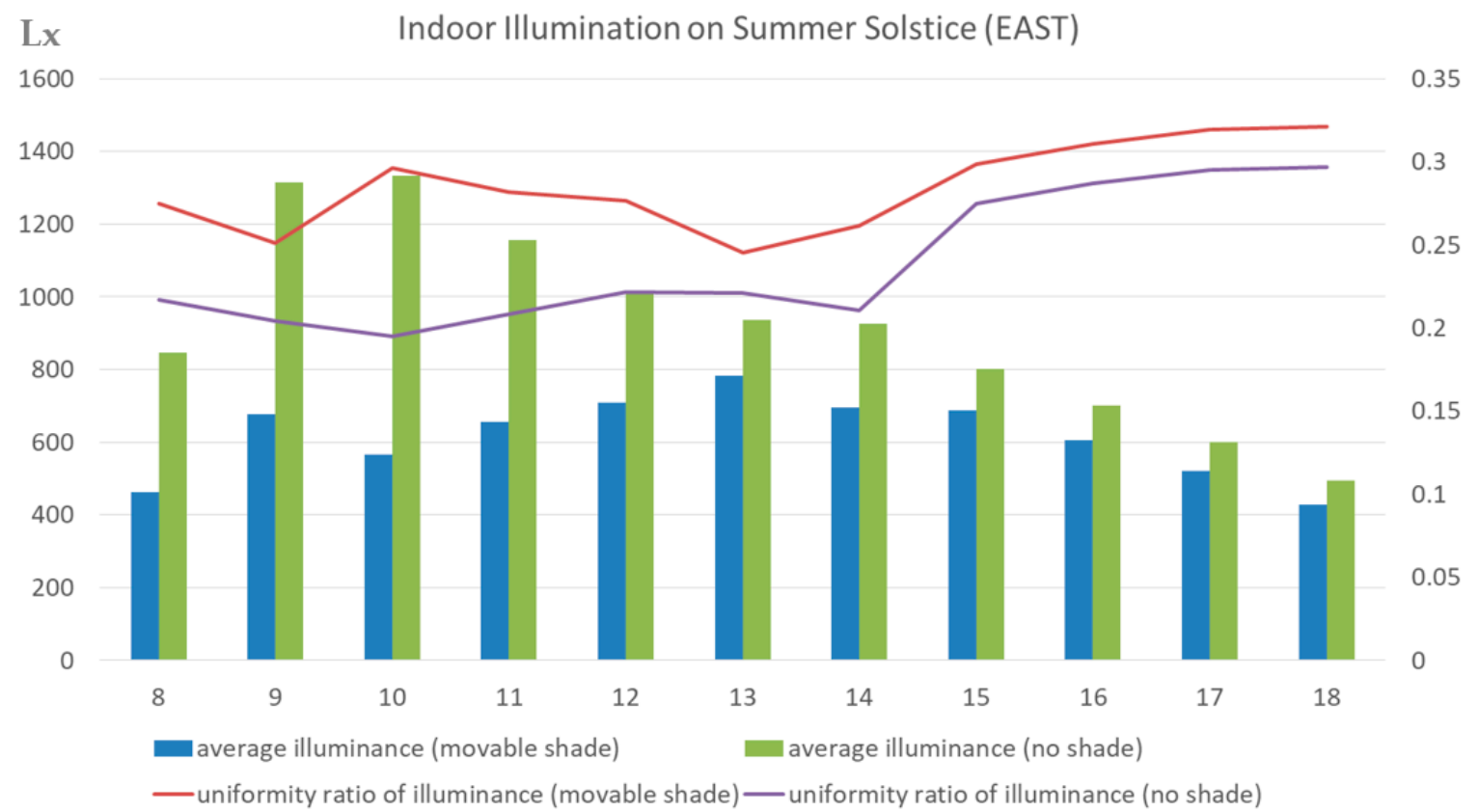

Figure 16. Indoor illumination analysis on summer solstice (east-facing window).

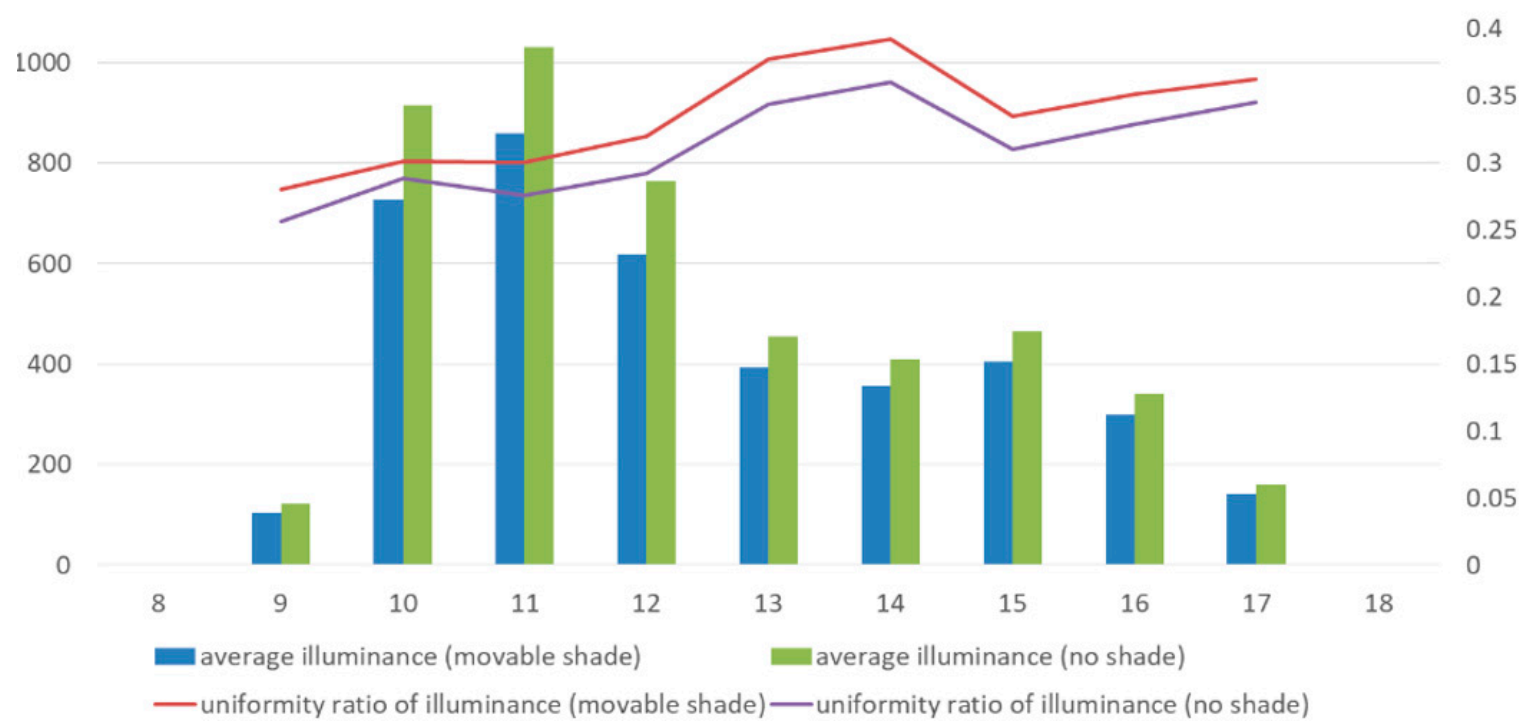

Figure 17. Indoor illumination analysis on winter solstice (east-facing window).

\subsubsection{Radiation Reduction Evaluations Results}

As shown in Figure 10, in the case of the summer solstice on south-facing window, the solar shielding rate of $100 \%$ is the most effective in reducing the cooling load. Compared with no shading, the solar radiation was highest at 14:002, and it was confirmed that the maximum solar radiation could be reduced by $42.73 \%$ with the installation of a four-axis movable shading device. In the case of the south window, as shown in Figure 10, the shape changes according to the sun's trajectory from 9:00 to 15:00, during which the radiation reduction rate reaches a maximum of $52.40 \%$ at 13:00. At 13:00 direct solar radiation changes from $0.389 \mathrm{kwh} / \mathrm{m}^{2}$ to $0.185 \mathrm{kwh} / \mathrm{m}^{2}$. In other time zones where $100 \%$ shielding area can be achieved even when projecting to the default value of $200 \mathrm{~mm}$, radiation reduction rates of 
$17.81 \%$ to $23.21 \%$ are achieved. Through this, the direct solar blocking effect of the movable shade can be confirmed, and it can be seen that direct solar can be avoided more effectively as the shape changes.

In the case of east-facing window on the summer solstice, as shown in Figure 11, direct solar radiation is only affected by noon, with a decrease of $57.20 \%$ direct solar radiation at 10:00 and the value drops to $24.70 \%$ at $13: 00$. Due to the limitation of the maximum protrusion length, the shielding rate is only $32.84 \%$ to $88.23 \%$ from $8: 00$ to $11: 00$, as described in Table 3, but it shows a high solar radiation reduction rate ranging from $43.43 \%$ to $57.20 \%$. The shape of the shade created at noon is the set of 400, 500, 300, and 200 with $99.78 \%$ coverage and 31.23\% solar reduction rate. From 13:00 on the east-facing window, the default value of $200 \mathrm{~mm}$ canopy is $100 \%$ shielding and solar radiation reduction effect is $24.70 \%$ to $64.17 \%$.

Direct solar reduction rates of more than $50 \%$ were obtained at the time of strongest solar radiation in both the south-facing and east-facing windows. As a result, it was confirmed that the direct solar radiation was controlled below $0.245 \mathrm{kwh} / \mathrm{m}^{2}$ through the installation of the sun shade.

\subsubsection{DGP Reduction Evaluation Results}

As shown in Figure 12, shade was required for controlling the light environment based on the result of the morphological derivation on the winter solstice. In the case of south-facing windows, the absence of shade results in the problem of glare from 10:00 to 15:00 on the winter solstice. According to the results summarized in Table 2, P2 or P3 had to be projected by 550 to $800 \mathrm{~mm}$, the maximum protrusion length, from 10:00 to 15:00. The solar shielding rate of the shade that satisfies the minimum DGP ranges from $14.67 \%$ to $32.64 \%$ at the said time period in the case of the south-facing window, as shown in Table 2. This signifies that, since the meridian altitude of the sun is low in winter, the movable shades are sufficient enough to solve the problem of glare caused by vertical incidence. The most protruding lengths of the shades, which were derived for the prevention of glare, were 10:00 and 15:00. At that time, the DGP reduction rates were $7.22 \%$ and $7.63 \%$, respectively.

In the case of east-facing windows, glare was the problem at 10:00, and the shade, which could prevent glare during the said time, has the shielding rates of $19.72 \%$, as shown in Table 3 . This shows that in the case of east-facing windows, even a relatively short protrusion length can prevent glare all day. At 10:00, there was a 6.87\% DGP reduction effect by installing a sunshade with a P2 protruding length of $350 \mathrm{~mm}$. At 11:00 and 12:00, the DGP was less than 0.35 without the shade, but the DGP reduction effect of $5.85 \%$ and $5.18 \%$ was achieved even with the default $200 \mathrm{~mm}$ shade.

In terms of the thermal environment, the winter sunshade is disadvantageous to the heating load, as it blocks solar radiation. However, as shown in Figures 12 and 13, maintaining a DGP of less than 0.35 for each hourly period has the effect of maintaining a pleasant visual environment. It was found that it was possible to solve the daylight glare problem during the winter season with the variable shade with the maximum length of $1000 \mathrm{~mm}$.

\subsubsection{Indoor Illuminance Evaluation Results}

As shown in Figures 14 and 15, it was also found that the average illuminance of the south-facing window when applying time period-based sorting and filtered shading device during the summer and winter solstices mostly satisfies the office interior illuminance standard (500 lx ) without artificial light. The time periods with an average illuminance of $500 \mathrm{~lx}$ or less are 8:00 and 18:00 on the summer solstice, and from 8:00 to 9:00, and after 17:00 on the winter solstice. Of these, 18:00 on the summer solstice is the average illuminance over $500 \mathrm{~lx}$ when there is no default shade of $200 \mathrm{~mm}$ length. In other cases, the average illuminance is less than $500 \mathrm{~lx}$ even when there is no shade.

In the east-facing window, there is no direct light in the afternoon, so it is necessary to look at changes in illuminance during the morning hours. As shown in Figures 16 and 17, the time when the mean illuminance does not meet $500 \mathrm{~lx}$ is 8:00 on the summer solstice, from 8:00 to 9:00. and after 13:00 on the winter solstice. Among these, the indoor illuminance is dropped below $500 \mathrm{~lx}$ by a proposed shade at 8:00 on the summer solstice. At 9:00 and 10:00, when the maximum protrusion point reaches 
$1000 \mathrm{~mm}$ on the summer solstice, the intensity of morning light changes greatly. However, there is little change in illuminance value because it is the shade of $200 \mathrm{~mm}$, which is the default value except for 10:00 on the winter solstice.

Taken together, the average illuminance drops below $500 \mathrm{~lx}$ due to shade at 18:00 on the summer solstice for south-facing window and 8:00 on the summer solstice for east-facing window. In addition, since the sun's altitude was low in winter, the change in average illuminance by the shade was small. This confirms that there was a little problem of increased lighting load resulting from lower indoor illuminance due to the proposed movable shades.

In addition, it was also examined whether the proposed shades improve the uniformity ratio of illuminance. The illuminance uniformity refers to an index used to measure how evenly illuminance is visually maintained, which is calculated by dividing the lowest illuminance value at the measurement point by the overall average. According to the results, the shades improve the uniformity of both southand east-facing rooms in summer and winter, when evaluated by the criteria of the proper uniformity ratio of 0.25 or above, except the period from 11:00 to 15:00 in the case of the south-facing window on the winter solstice. This suggests that the shape of the shade derived from glare prevention in the south window during winter was successful in reducing the DGP value to below 0.35 , which is the main goal of the light environment in this study, but did not improve the illuminance uniformity. However, due to the strong light of the sun and low sun altitude, the indoor illumination is high and the uniformity is low. Therefore, it seems that there is a limit to improving the illuminance uniformity with movable shading proposed in this study, and further research is needed on this part.

\section{Conclusions}

This study devised a surround-type exterior movable shading system and developed an algorithm that could generate appropriate shapes of sunshade for each time period in order to save energy in summer and improve the light environment in winter. The integrated algorithms of Grasshopper-Ladybug-Octopus was used to derive the optimal shapes of shade for each time period based on the orientation of the room and the position of the sun. With regard to the sunshades derived from the genetic algorithm, the study analyzed changes in radiation, illuminance, and DGP according to different orientations, and the results are as follows:

First, on the summer solstice, shade shapes with shielding areas of almost $100 \%$ should be derived to achieve the most effective reduction of the direct solar radiation, while on the winter solstice, it was important to derive the shapes that can prevent glare to improve comfort in the indoor light environment. The proposed movable shade reduced direct solar radiation by $52.40 \%$ and $57.20 \%$ in the south- and east-facing windows, respectively. In addition, during the glare-prone time period, it was possible to derive the shade shape that had the shortest protrusion length and dropped the DGP below 0.35 . However, the installation of a shade leads to the reduction of solar radiation on the winter solstice, which could increase the heating load to some degree.

Second, due to the features of the shades proposed in this study (the maximum protrusion length of shading devices was set at $1000 \mathrm{~mm}$ ), shade shapes with shielding areas of almost $100 \%$ could be generated at south-facing windows on the summer solstice, whereas east-facing shades protruded to $1000 \mathrm{~mm}$ could only shield $46.49 \%$ and $79.13 \%$ of the area at 9:00 and 10:00, respectively. Despite the incomplete shielding capacity, it was demonstrated that east-facing shades can lower direct solar radiation by $56.59 \%$ and $57.20 \%$, a significant effect of shielding solar radiation as compared with cases where there are no shades at the time period. Even if the shielding rate could not be secured $100 \%$ due to the limitation of the length, a significant solar radiation reduction effect could be confirmed.

Third, the results of the DGP analysis show that the application of shades significantly improved indoor glare problems as compared with cases without any shade. The installation of the shade made it possible to drop the DGP below 0.35. On the summer solstice, there was no problem in south- and east-facing shades and cases with no shades, except 8:00 in the east-facing window. While on the winter solstice, the problem of glare arises from 10:00 to 15:003 on the south-facing windows and 10:00 
on the east-facing windows, and it was possible to derive the shapes of shades that could address the said problem.

According to the average illuminance analysis, there is a time when the illuminance value does not reach $500 \mathrm{Lx}$ and the average illuminance value decreases due to the installation of the sunshade. At 18:00 in the south-facing window and at 8:00 in the east-facing window, the average illuminance dropped below $500 \mathrm{Lx}$ due to the shade. The uniformity ratio of illuminance was found to be improved in all sections except for 10:00 to 15:00 in the south-facing window, where the shading purpose was to prevent glare.

This study conducted the analysis of thermal and light environments through the simultaneous simulation of shape generation and environmental performance by applying shading devices whose shapes change at different time periods according to the trajectory of the sun. However, there are certain limitations in this study, as it restricted the simulation period to the summer and winter solstices in calculating energy savings and improvement of the indoor light environment. Thus, the time scope should be expanded to include the spring and autumn equinoxes, and accordingly accompanied by performance evaluation on thermal and light environments of shading devices. In addition, since variables such as width-to-height ratio of a window and the window-to-floor ratio result in significant differences in thermal and light environments, the window-to-floor ratio is seen as a factor. Therefore, a broader study regarding these factors should be conducted in the future.

Author Contributions: Conceptualization, H.-J.K. and H.J.M.; methodology, H.-J.K. and C.-S.Y.; computer simulation, C.-S.Y.; investigation, H.-J.K. and C.-S.Y.; writing and editing, H.-J.K.

Funding: This work was supported by the Korea Institute of Energy Technology Evaluation and Planning (KETEP) and the Ministry of Trade, Industry \& Energy (MOTIE) of the Republic of Korea (no. 20172020109130); the National Research Foundation of Korea (NRF) grant funded by the Korea government (MSIT) (No. 2018R1A2B6008682); and the Architecture \& Urban Development Research Program funded by Ministry of Land, Infrastructure and Transport of Korean government (No. 19AUDP-B099686-05).

Conflicts of Interest: The authors declare no conflict of interest.

\section{References}

1. Roel, C.G.M.L.; Fabio, F.; Hensen, J.L.M.; Mauro, O. Review of current status, requirements and opportunities for building performance simulation of adaptive facades. J. Build. Perform. Simul. 2017, 10, 205-223.

2. Choi, S.J.; Lee, D.S.; Jo, J.H. Lighting and cooling energy assessment of multi-purpose control strategies for external movable shading devices by using shaded fraction. Energy Build. 2017, 150, 328-338. [CrossRef]

3. Lim, S.H.; Kim, G. Predicted performance of shading devices for healthy visual environment. Indoor Built Environ. 2010, 19, 486-496.

4. Lim, Y.-W.; Mohd, Z.K.; Mohd, H.A.; Dilshan, R.O.; Aminatuzuhariah, M.A. Building façade design for daylighting quality in typical government office building. Build. Environ. 2012, 57, 194-204. [CrossRef]

5. Aldawoud, A. Conventional fixed shading devices in comparison to an electrochromic glazing system in hot, dry climate. Energy Build. 2013, 59, 104-110. [CrossRef]

6. Laura, B.; De Falco, F.; Minichiello, F. Effects of solar shading devices on energy requirements of standalone office buildings for Italian climates. Appl. Therm. Eng. 2013, 54, 190-201.

7. Bellia, L.; Francesco, C.M.; Pedace, M.A. An Overview on Solar Shading Systems for Buildings. Energy Procedia 2014, 62, 309-317. [CrossRef]

8. Ayca, K.; Basak, K.K.; Ioannis, C.; Sevil, S. Review of simulation modeling for shading devices in buildings. Renew. Sustain. Energy Rev. 2016, 53, 23-49.

9. Kim, G.; Lim, H.S.; Lim, T.S.; Schaefer, L.; Kim, J.T. Comparative advantage of an exterior shading device in thermal performance for residential buildings. Energy Build. 2012, 46, 105-111. [CrossRef]

10. Choi, S.J.; Lee, D.S.; Jo, J.H. Methods of Deriving Shaded Fraction According to Shading Movements of Kinetic Facade. Sustainability. 2017, 9, 1449. [CrossRef]

11. Niccolò, A.; Junia, C.; Manlio, M. Comparative energy and economic performance analysis of an electrochromic window and automated external venetian blind. Energy Procedia 2012, 30, 404-413. 
12. Crawley, D.; Hand, J.; Kummert, M.; Griffit, B. Contrasting the Capabilities of Building Energy Performance Simulation Programs. Build. Environ. 2008, 43, 661-673. [CrossRef]

13. Tzempelikos, A.; Shen, H. Comparative control strategies for roller shades with respect to daylighting and energy performance. Build. Environ. 2013, 67, 179-192. [CrossRef]

14. Atzeri, A.; Cappelletti, F.; Gasparella, A. Internal versus external shading devices performance in office buildings. Energy Procedia 2014, 45, 463-472. [CrossRef]

15. Caldas, L. Generation of Energy-Efficient Patio Houses: Combining GENE_ARCH and a Marrakesh Medina Shape Grammar. In Proceedings of the 2011 AAAI Spring Symposium Series, Palo Alto, CA, USA, 21-23 March 2010; pp. 10-18.

16. Caldas, L.; Norford, L.K. A design optimization tool based on a genetic algorithm. Autom. Constr. 2002, 11, 173-184. [CrossRef]

17. Caldas, L. Generation of energy-efficient architecture solutions applying GENE_ARCH: An evolution-based generative design system. Adv. Eng. Inform. 2008, 22, 59-70. [CrossRef]

18. Tuhus-Dubrow, D.; Krarti, M. Genetic-algorithm based approach to optimize building envelope design for residential buildings. Build. Environ. 2010, 45, 1574-1581. [CrossRef]

19. Konis, K.; Gamas, A.; Kensek, K. Passive performance and building form: An optimization framework for early-stage design support. Sol. Energy. 2016, 125, 161-179. [CrossRef]

20. Manza, M. Genetic Optimization of External Fixed Shading Devices. Energy Build. 2014, 72, 431-440. [CrossRef]

21. Gonzales, J.; Fiorito, F. Daylighting Design of Offfice Buildings: Opimization of External Solar Shading bu Using Conbined Simualation Methods. Buildings 2015, 5, 560-580. [CrossRef]

22. Zani, A.; Andaloro, M.; Deblasio, L.; Ruttico, P.; Mainini, A. Computational design and parametric optimization approach with genetic algorithms of an innovative concrete shading device system International High-Performance Built Environment Conference-A Sustainable Built Environment Conference. Procedia Eng. 2016, 180, 1473-1483. [CrossRef]

23. Hopkinson, R.G. Glare from Daylighting in Buildings. Appl. Rgon. 1972, 3, 206-215. [CrossRef]

24. Wienold, J.; Christoffersen, J. Evaluation methods and development of a new glare prediction model for daylight environments with the use of ccd cameras. Energy Build. 2006, 38, 743-757. [CrossRef] 